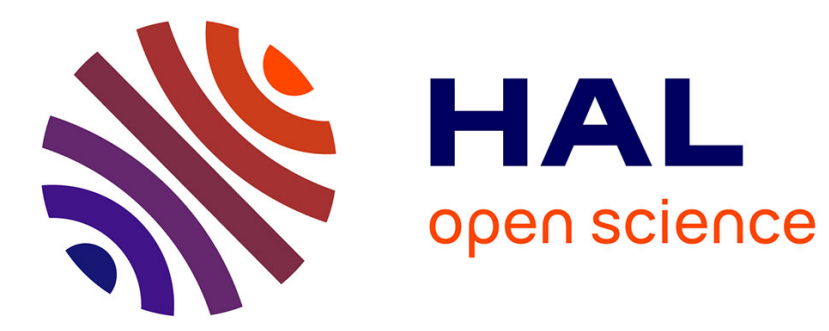

\title{
Pollution in a globalized world: Are debt transfers among countries a solution?
}

\author{
Marion Davin, Mouez Fodha, Thomas Seegmuller
}

\section{To cite this version:}

Marion Davin, Mouez Fodha, Thomas Seegmuller. Pollution in a globalized world: Are debt transfers among countries a solution?. 2019. halshs-02303265v2

\section{HAL Id: halshs-02303265 \\ https://shs.hal.science/halshs-02303265v2}

Preprint submitted on 23 Jun 2020

HAL is a multi-disciplinary open access archive for the deposit and dissemination of scientific research documents, whether they are published or not. The documents may come from teaching and research institutions in France or abroad, or from public or private research centers.
L'archive ouverte pluridisciplinaire HAL, est destinée au dépôt et à la diffusion de documents scientifiques de niveau recherche, publiés ou non, émanant des établissements d'enseignement et de recherche français ou étrangers, des laboratoires publics ou privés. 


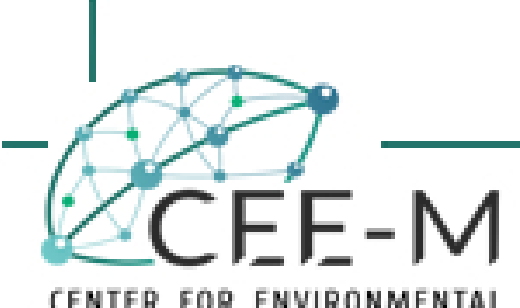

\title{
Pollution in a globalized world: Are debt transfers among countries a solution?
}

\author{
Marion Davin \\ Mouez Fodha \\ $\&$ \\ Thomas Seegmuller
}

CEE-M Working Paper 2019-20 


\title{
Pollution in a globalized world: Are debt transfers among countries a solution?*
}

\author{
Marion Davin ${ }^{\dagger}$, Mouez Fodha ${ }^{\ddagger}$ and Thomas Seegmuller ${ }^{\S}$
}

October 1, 2019

\begin{abstract}
This article analyzes the impacts of debt relief on production and pollution. We develop a two-country overlapping generations model with environmental externalities, public debts and perfect mobility of assets. Pollutant emissions arise from production, but agents may invest in pollution mitigation. Could debt relief be an efficient tool to encourage less developed countries to engage in the fight against climate change? We consider a decrease of the debt of the poor country balanced by an increase of the richer country's debt. We show that debt relief makes it possible to engage poor countries in the process of pollution abatement. Capital, environmental quality and welfare can increase in both countries. This result relies on the environmental sensitivity and the discount factor in the poor country relative to the rich one: the greater they are the more beneficial the debt relief is.
\end{abstract}

JEL classification: F43, H23, Q56.

Keywords: Pollution; Abatement; Overlapping generations; Public debt; Capital market integration.

\section{Introduction}

The trend in $\mathrm{CO}_{2}$ emissions predicts a global temperature increase of more than $3^{\circ} \mathrm{C}$ by the end of the century with severe consequences. Loss of agricultural yield, loss of biodiversity, sea level rise, climate migration, extreme weather events... are all phenomena that will increase and the brunt of the economic damages will be probably borne by poorest countries (Schelling, 1992;

${ }^{*}$ We would like to thank the participants at the conferences LAGV 2019, PET 2019 and EAERE 2019 for their helpful comments. This work has been carried out thanks to the financial support of the French National Research Agency (ANR-15-CE33-0001-01 and ANR-16-CE03-0005).

${ }^{\dagger}$ CEE-M, Univ Montpellier, CNRS, INRA, SupAgro, Montpellier, France. E-mail: marion.davin@umontpellier.fr

${ }^{\ddagger}$ Corresponding author. University Paris 1 Panthéon-Sorbonne and Paris School of Economics. PjSE, 48 Boulevard Jourdan, 75014 Paris, France. E-mail: mouez.fodha@univ-paris1.fr.

§ Aix-Marseille University, CNRS, EHESS, Centrale Marseille, AMSE. 5-9 Boulevard Bourdet, CS 50498, 13205 Marseille Cedex 1, France. E-mail: thomas.seegmuller@univ-amu.fr. 
Mendelsohn, et al., 2006). To achieved a $1.5^{\circ} \mathrm{C}$ consistent pathway, the international community calls for immediate global response. Meeting this challenge would require to accelerate the deployment of mitigation actions and to have an active participation of all countries (see Coninck et al., 2018). Regarding engagement of countries, important disparities prevail, as illustrated by Table 1 that presents the Environmental Performance Index (EPI) for climate and energy for several countries. This index provides a good proxy of country's environmental engagement.

\begin{tabular}{|l|l||l|l|}
\hline Countries & Index & Countries & Index \\
\hline Switzerland & 90.55 & Republic Czech & 54.65 \\
\hline Sweden & 86.8 & Ireland & 54.16 \\
\hline France & 70.46 & Netherlands & 52.55 \\
\hline China & 68.62 & South Korea & 46.75 \\
\hline Spain & 67.77 & United States of America & 45.81 \\
\hline Denmark & 67.56 & Japan & 45.08 \\
\hline Italy & 65.14 & India & 44.77 \\
\hline Poland & 64.33 & Greece & 42.17 \\
\hline Norway & 63.58 & Turkey & 39.99 \\
\hline United Kingdom & 63.06 & Canada & 39.88 \\
\hline Austria & 62.79 & Brazil & 33.24 \\
\hline Portugal & 62.33 & Burkina Faso & 26.24 \\
\hline Germany & 55.47 & Madagascar & 16.23 \\
\hline
\end{tabular}

Table 1 - The Climate $\mathscr{G}$ Energy Environmental Performance Index (EPI), 2018. https: //epi. envirocenter. yale. edu/

Environmental objectives are a particular concern for poor countries in which the environmental challenges are compounded by high levels of external economic vulnerability and public debt. They recurrently use public debt to absorb the impact of external macroeconomic shocks and, now, of more frequent natural disasters. In turn, higher levels of public debt associated with weak macroeconomic situation increase fiscal pressure and constrain the capacity of countries to address vulnerabilities and to mitigate pollution. According to IMF classification, a large part of poor countries presents a high risk of experiencing a debt crisis, what underlines the importance to compose with countries debt profiles to address environmental challenge. ${ }^{1}$

When we examine the diversity of instruments used to provide climate finance, debt transfers, in the form of debt reliefs granted by developed countries to developing one, currently represent only an insignificant proportion of financing strategies (see the Table 2 built by Fenton et al., 2014).

Question then arises, does a debt transfer in favor of less developed countries is a relevant macroeconomic policy lever to accompany environmental actions? This article contributes to this question by using a theoretical approach combining debt transfers and global pollution issues. We aim at analyzing the consequences of a debt transfer from rich to poor countries on mitigation

\footnotetext{
${ }^{1}$ See the debt sustainability framework of IMF and World Bank for public and external debt sustainability analysis in low-income countries.
} 


\begin{tabular}{|c|c|c|}
\hline Financial instruments & Amount (million, US\$) & Share \\
\hline Grants and related instruments & 14379.1 & $45.2 \%$ \\
\hline Unknown & 614.4 & $1.9 \%$ \\
\hline Multiple & 419.3 & $1.3 \%$ \\
\hline Loans, guarantees and insurance & 14840.2 & $46.7 \%$ \\
\hline Debt relief & 82.5 & $\mathbf{0 . 3} \%$ \\
\hline Capital contribution & 1457.4 & $4.6 \%$ \\
\hline Total & 31792.9 & $100 \%$ \\
\hline
\end{tabular}

Table 2 - Instrument used to fulfill climate finance commitments.

From "Debt relief and financing climate change action", A. Fenton, H. Wright, S. Afionis, J. Paavola and S. Huq, Nature Climate Change (4), 2014. Based on data collected by the World Resource Institute http: //go. nature. com. inshs. bib. cnrs. fr/rMhVxK

decision of agents, as well as on pollution, GDP and well-being.

We develop a two-country overlapping generations (OLG) model with global pollution externalities and private mitigation. Production deteriorates the environmental quality, harming the welfare of future generations. There is a perfect mobility of assets between countries. In line with arguments previously presented, countries exhibit different macroeconomic profiles. They have different saving rates, heterogeneous green awareness as well as productivities. In addition, they are characterized by a different level of debt, which is financed by a tax on agents' income and by new debt emissions. To keep the analysis simple, we do not formalize public spending for environmental protection, such that fiscal pressure is mainly determined by the debt level. The relative productivity between countries determines their profile: we define the poor (resp. the rich) country as those with the lower (resp. the higher) level of productivity.

To limit the effects of macroeconomic policy on fully integrated financial markets, we assume that overall debt remains constant. This implies a constant global debt supply and no direct effect of the debt policies on the international interest rate, even if it does not exclude composition effects of debt among countries. This assumption can also be seen as a way to rule out unsustainable global debt.

Accordingly, we study the environmental and economic consequences of a debt relief in favor of the poorer country, founded by the richer country. Our research question leads us to focus on situations in which, without any transfer, the poor country does not engage in environmental action while the rich one does it. We show that debt relief for this less involved country is never sufficient to lead him to engage in the process of pollution abatement when its sensitivity to environmental quality is low. When green awareness in the poor country is high enough, a debt transfer can induce him to engage in actions to fight against climate change. This result is confirmed even when the aid donor country faces high level of debt, as are most North-American and Western European countries. In any case, such a policy can be good for both capital accumulation and the environment depending on the preferences of the different countries. The debt transfer translates into income tax variation and hence implies a redistribution of net income 
between countries. Given that bonds are used as debt instrument, the debt level has an effect on the capital market equilibrium. It affects debt services, and therefore, the level of taxes. If the poor country is the more patient, it increases net income and saving for the recipient while reduces it for the donor. As poor and rich countries share a common international asset market, global saving, capital stock and hence global pollution abatement increases only if the transfer is in favor of the population that saves more. In such a case, welfare benefits are clear for the recipient. However, when the poor country is relatively impatient, it is not appropriate to implement a debt transfer without any other economic and environmental actions, because even if it can help him to engage in mitigation activities, the transfer reduces the global stock of capital and the global level of effort to mitigate pollution. As the efficiency of abatement activities in reducing emission is sufficiently important, the policy is damaging for environmental quality. Our analysis sustains the interest of debt reliefs to address climate change issues, by providing the conditions under which a debt transfer is an efficient macroeconomic instrument to promote environmental actions.

As we have seen, our paper adopts a theoretical approach to contribute to two strands of the economic literature, namely the interplay between public debt and environmental quality, and the links between economic development and the environment in an international context. Connecting these two strands, we provide new intuitions about the effects of international transfers on welfare and the environment.

Debt financing has been introduced in dynamic models with environmental concerns (Bovenberg and Heijdra, 1998; Heijdra et al., 2006; Fernandez et al., 2010). Debt policy only makes possible to redistribute welfare gains from future to existing generations: there is no debt financing of the pollution mitigation sectors. Fodha and Seegmuller $(2012,2014)$ and Fodha et al. (2018) analyze debt financing schemes for public and private mitigation. They show that efficient environmental tax reforms may be designed. This existing literature, however, considers closed economies, which is a limitation as capital markets are interconnected and globalized, as climate.

Our work complements prior contributions that deal with global environmental issues in international frameworks. This paper most directly extends three existing papers. John and Pecchenino (1997) focus on the effects of cooperation between two countries in mitigating global pollution. Their approach is simpler because there is no capital or savings arbitrage and they only assume lump-sum transfers between countries. They conclude that the developing countries must be compensated for their environmental expenditures. In our article, we focus on financial markets and debt levels. Debt reduction is interesting because it has two effects. A direct one plays the same role as a lump-sum transfer of income. An indirect one goes through the debt service reduction. The second is the work of Bednar-Friedl et al. (2010). Countries differ in their levels of public debt per capita such that one country is a net creditor and the other one is a net debtor to the world economy. They find that if the country which unilaterally reduces its emissions permits is a net creditor to the world economy, the domestic welfare costs are smaller and the foreign welfare costs are larger than if it was a net debtor. While in this work mitigation efforts 
are exogenous, we differ by taking into account endogenous mitigation expenditure. Especially, we study in details the effect of debt transfers when one country makes no effort to reduce its net emissions. Third, Muller-Furstenberger and Schumacher (2017) propose a dynamic model where all agents contribute to a global externality, but only those in a specific region suffer from it. They develop an overlapping generations model with two types of agents. In the non integrated economy, even though agents have the same technologies, if agents affected by the externality are sufficiently poor in terms of initial capital endowments, they may be stuck in an environmental poverty trap. Capital market integration helps to eliminate it. This article, although close to our work, considers heterogeneity in the consequences of the climate change while we are interested in heterogeneity in preferences. Moreover, in addition to the integrated capital market assumption, we add public debt that influences savings and capital accumulation.

The consequences of international transfers have been particularly examined in the development economic literature, to see if it provides development support for indebted countries. While direct aid to poor countries are often criticized (see e.g Boone, 1996; Burnside and Dollar, 2000; Rajan and Subramanian, 2006; Dreher and Langlotz, 2017), Cassimon et al. (2015) and Channing et al. (2016) conclude that the gains from debt cancellation promote health spending, public investment, and tax mobilization within the recipient countries. We extend the discussion by considering climate change issues and we give conditions such that untied debt cancellation promotes also environmental quality and GDP per capita worldwide.

The literature has also questioned the characteristics of international transfers to protect the environment. Baraano and San Martin (2015) develop a dynamic equilibrium model in which public investments in both infrastructure and pollution abatement can be financed using international aid. They find that transfers linked to both infrastructure and pollution abatement may be the best welfare-enhancing alternative. Sakamoto et al. (2017) show that financial aid to enhance adaptation capacity of vulnerable countries is efficient. They find that Norths assistance to South can facilitate pollution mitigation in both regions. Another branch of the literature consider the interplay between environmental finance and development aid transfers. Bretschger and Suphaphiphat (2014) develop a two country growth model with two policy outcomes: climate mitigation by the North to reduce global pollution and traditional development aid under the form of income transfer. Because of low learning capacities in the South, they obtain that income transfer is without effect on growth while active climate policy favors capital accumulation in both countries and hence growth. In the same vein, Eyckmans et al. (2016) develop a theoretical model in which North-South development transfers are complemented by mitigation and adaptation transfers. Concerning the effects of a transfer for mitigation support, they underline that climate change finance works as a pure income transfer, without effectiveness in terms of emission cuts unless associated with matching grant. In our article, we depart from this literature as we limit aid transfers to untied debt cancellation while technology against pollutant emission corresponds to mitigation. Our work differs from these contributions by highlighting the role of private agents in mitigation decisions, which depend on individuals preferences and net income. 
Finally, in our paper, debt relief is undertaken without any counterpart. Hence, our model does not take into account debt for nature swaps (Deacon and Murphy, 1997; Cassimon et al., 2011, 2014). The literature on economic development underlines the inefficiencies of this type of aid as soon as donor country monitoring is not put in place. The risk of inefficiency of this policy is all the higher as the country faces problems of quality governance, or extreme poverty. We show the possibility of economic and environmental improvements even if debt relief is considered without promise of any environmental action.

The rest of this paper is organized as follows. Section 2 presents the two-country OLG model with environmental externalities. Section 3 defines the equilibrium. Section 4 studies the situations where agents in the poor country have a weak environmental sensitivity. Section 5 presents the opposite configuration. Technical details are relegated to an Appendix.

\section{The model}

The world consists of two competitive economies indexed by $i \in\{D, F\}$. Within each country, a new generation of two-period lived agents is born at each period of time. Therefore, two generations alive in each period $t$ : the workers and the retired people. In each country, the population size of the generation is constant and normalized to one. There is no mobility of labor between countries, whereas there is a perfect mobility of the assets and the unique final good, as for instance in Persson (1985). The assumption of perfect capital mobility can be seen as a good approximation of what happens in countries with highly integrated financial markets and few capital controls. ${ }^{2}$

\subsection{Environmental quality}

We consider the environment as a global public good, such as climate. We measure the evolution of this aggregate by an index, which deteriorates with pollution from global production and improves with private abatement. We assume that both the rates of pollutant emissions and the rates of abatement are equal among countries. In addition, we neglect natural degradation, so the environment is a stock whose accumulation varies with net pollution. Mitigation consists in reducing greenhouse gas emissions into the atmosphere, by increasing energy efficiency, replacing fossil fuels with new energies and enhancing the sinks that capture and store these gases. Mitigation could be reforestation, insulation of buildings or the development of carbon capture and sequestration technologies. Global environmental quality $E_{t}$ evolves according to:

$$
E_{t+1}=E_{t}-\theta\left(y_{D t}+y_{F t}\right)+\phi\left(a_{D t}+a_{F t}\right)
$$

where $y_{i t}$ and $a_{i t}$ represent production and abatement of country $i$ respectively, and $E_{0}>0$. The pollution flow resulting from production is given by the emission factor $\theta>0$ and efficiency of

\footnotetext{
${ }^{2}$ At the end of Section 5.2, we will provide intuitions about the mechanisms that operate when capital mobility between countries is not prefect to compare with the situation with perfect mobility.
} 
abatement is given by factor $\phi>0$. We keep these parameters equal in order to focus on the role played by debt, savings and mitigation decisions. Taking into account different values for these parameters would be possible, but would only accentuate the effects of specialization. The country with a high $\phi$ would have to mitigate, while the country with a low $\theta$ would have to produce more.

\section{$2.2 \quad$ Firms}

In each country, producers use capital and labor for the production of a unique final good, which is the numéraire. The technology used is Cobb-Douglas. Taking into account that labor is unit, the production function writes $y_{i t}=A_{i} k_{i t}^{\alpha}$, where $k_{i t}$ denotes capital, $A_{i}>0$ the global productivity and $\alpha \in(0,1)$ the capital share in income. Profit maximization gives:

$$
\begin{aligned}
& w_{i t}=(1-\alpha) A_{i} k_{i t}^{\alpha} \\
& R_{i t}=\alpha A_{i} k_{i t}^{\alpha-1}
\end{aligned}
$$

with $w_{i t}$ the wage and $R_{i t}$ the return of capital in country $i .^{3}$

\subsection{Households}

A generation born at period $t$ derives utility from consumption when young $c_{i t}$ and old $d_{i t+1}$ and from environmental quality at both periods. Accordingly, the lifetime utility is given by:

$$
\ln c_{i t}+\beta_{i} \ln d_{i t+1}+\delta_{i} \ln E_{t}+\gamma_{i} \ln E_{t+1}
$$

where $\beta_{i} \in(0,1)$ denotes the discount factor in country $i$, and $\delta_{i} \geqslant 0$ and $\gamma_{i} \geqslant 0$ the sensitivity to environmental quality when young and old respectively. We assume that these preference parameters are country specific, which means that $\beta_{D} \neq \beta_{F}, \delta_{D} \neq \delta_{F}$ and $\gamma_{D} \neq \gamma_{F}$. On the one hand, heterogeneity between $\beta_{i}$ is empirically supported by the work of Wang et al. (2016), which present results from a large-scale international survey on time preference, conducted in 53 countries, and find that the waiting tendency is correlated with country specific characteristics, like innovation, environmental protection, and crediting rating. On the other hand, $\delta_{i}$ and $\gamma_{i}$ aggregate both sensitivity and vulnerability to climate change which are also different among rich and poor countries (Schelling, 1992; Mendelsohn et al., 2006).

When young, each agent inelastically supplies one unit of labor and receives real wage $w_{i t}$. A lump-sum tax $\tau_{i t}$ is levied on this income, which is shared between consumption $c_{i t}$, savings $s_{i t}$ and private abatement $a_{i t}$, as in John and Pecchenino (1994). Indeed, young people take care about the environmental quality they will face when old, but suffer from the past accumulation of pollution. Consumption when old $d_{i t+1}$ is entirely financed by the remunerated savings.

\footnotetext{
${ }^{3}$ For simplification and taking into account the duration of a period, we assume full depreciation of capital after one period of use.
} 
Therefore, the two budget constraints faced by an agent born at period $t$ write:

$$
\begin{aligned}
c_{i t}+s_{i t}+a_{i t} & =w_{i t}-\tau_{i t} \\
d_{i t+1} & =R_{i t+1} s_{i t}
\end{aligned}
$$

A young agent maximizes her utility (4) taking into account the two budget constraints (5) and (6), the environmental quality (1) and the non-negativity of abatement $a_{i t} \geqslant 0$. We obtain:

$$
\begin{aligned}
& d_{i t+1}=\beta_{i} R_{i t+1} c_{i t} \\
& E_{t+1} \geqslant \gamma_{i} \phi c_{i t}, \text { with an equality when } a_{i t}>0
\end{aligned}
$$

which also ensures $E_{t+1}>0$ for all $t \geqslant 0$.

We deduce that we have two main situations. Either $a_{i t}>0$ and:

$$
\begin{aligned}
& s_{i t}=\frac{\beta_{i}}{\gamma_{i} \phi} E_{t+1}, \quad c_{i t}=\frac{E_{t+1}}{\gamma_{i} \phi}, \quad d_{i t+1}=\frac{\beta_{i}}{\gamma_{i} \phi} R_{i t+1} E_{t+1} \\
& a_{i t}=w_{i t}-\tau_{i t}-\frac{1+\beta_{i}}{\gamma_{i} \phi} E_{t+1}
\end{aligned}
$$

or $a_{i t}=0$ and:

$$
\begin{aligned}
s_{i t} & =\frac{\beta_{i}}{1+\beta_{i}}\left(w_{i t}-\tau_{i t}\right), \quad c_{i t}=\frac{1}{1+\beta_{i}}\left(w_{i t}-\tau_{i t}\right) \\
d_{i t+1} & =\frac{\beta_{i}}{1+\beta_{i}} R_{i t+1}\left(w_{i t}-\tau_{i t}\right), \quad E_{t+1}>\frac{\gamma_{i} \phi}{1+\beta_{i}}\left(w_{i t}-\tau_{i t}\right)
\end{aligned}
$$

When environmental quality is high enough with respect to the net income, an agent has no incentive to mitigate pollution. In contrast, if the net income is high enough and environmental quality too low, she engages in abatement activities. The latter case is all more likely as $\gamma_{i}$ is high.

\subsection{Government}

The evolution of public debt in domestic and foreign countries and its consequences, especially on economic growth, is a major economic concern. Public debt issues are also included in international debates on the environment, in which the connection between public debt and the environment is recursively discussed. To keep analysis simple, we do not formalize public spending for environmental protection. Rather, we focus on interactions between public debt and the environment in an international context by assuming that final action to reduce global pollution is private. In this way, the government cannot directly use debt to finance future environmental quality and the direct link between public debt and environmental policy is ignored.

In each country, the government faces the following budget constraint:

$$
b_{i t+1}=R_{i t} b_{i t}-\tau_{i t}
$$


with the initial public debt level $b_{i 0} \geqslant 0$ given. The government collects lump sum tax $\tau$ on workers and uses bonds as debt instrument. Its expenditures include repayment of debt and interest payments.

\section{Equilibrium}

As international capital mobility is assumed to be perfect, foreign and domestic assets yield the same rate of return. Market clearing requires world savings equal to world investment:

$$
\begin{aligned}
R_{D t} & =R_{F t} \\
s_{D t}+s_{F t} & =k_{D t+1}+b_{D t+1}+k_{F t+1}+b_{F t+1}
\end{aligned}
$$

Given the production technologies in each country, the law of motion for environmental quality is given by:

$$
E_{t+1}=E_{t}-\theta\left(A_{D} k_{D t}^{\alpha}+A_{F} k_{F t}^{\alpha}\right)+\phi\left(a_{D t}+a_{F t}\right)
$$

and $E_{t}>0$. Using (3), equation (14) means that:

$$
k_{F t}=k_{D t}\left(\frac{A_{F}}{A_{D}}\right)^{\frac{1}{1-\alpha}}
$$

We will investigate policies where debt in both countries are exogenous policy parameters, i.e. $b_{D t}=b_{D}$ and $b_{F t}=b_{F}$ for all $t$, while $\tau_{D t}$ and $\tau_{F t}$ are endogenous and satisfy the government budgets. In this way, public debt is a policy variable and the economic sustainability of public debt is satisfied at each period. Equation (13) becomes:

$$
\tau_{i t}=\left(\alpha A_{i} k_{i t}^{\alpha-1}-1\right) b_{i}
$$

We consider a domestic economy richer than the foreign one. Numerous studies emphasize that the major part of the difference in incomes between rich and poor countries is due to differences in total factor productivity (see the survey by Caselli, 2005, and the study by Hsieh and Klenow, 2010).

Assumption $1 A_{D}>A_{F}$.

Despite this assumption on the productivities between countries, we do not impose any ranking on the respective debt levels, i.e. $b_{D}$ higher or smaller than $b_{F}$. We will in particular analyze the effect of an increase of $b_{D}$ which allows to decrease $b_{F}$. Such a measure implies a redistribution of income net of tax from the rich to the poor country, as the tax paid in each country linearly depends on $b_{i}$. However, we will see that the effects of a debt transfer quantitatively differ from a standard redistribution of income because it goes through different channels compare to a simple transfer of income. In addition, qualitative differences emerge if we consider imperfect capital mobility, as discussed at the end of Section 5.2. 
We focus on equilibria with $a_{D t}>0$ and either $a_{F t}>0$ or $a_{F t}=0$. Equilibria without any abatement activities are excluded from our analysis, while situations in which only one of the country do not invest in environmental protection are examined. Indeed, when both countries do not engage in mitigation, the net pollution flow is positive at each date, leading to a perpetual decrease in the quality of the environment that rules out any stationary equilibrium.

\subsection{Equilibrium with $a_{D t}>0$ and $a_{F t}=0$}

We focus here on an asymmetric equilibrium where only the domestic households are engaged in pollution mitigation. This means that:

$$
\frac{\phi \gamma_{D}}{1+\beta_{D}}\left[(1-\alpha) A_{D} k_{D t}^{\alpha}-\tau_{D t}\right]>E_{t+1}>\frac{\phi \gamma_{F}}{1+\beta_{F}}\left[(1-\alpha) A_{F} k_{D t}^{\alpha}\left(\frac{A_{F}}{A_{D}}\right)^{\frac{\alpha}{1-\alpha}}-\tau_{F t}\right]
$$

Using (2), (11), (10) and (17), equilibrium on the asset market (15) satisfies:

$$
\begin{aligned}
k_{D t+1}\left[1+\left(\frac{A_{F}}{A_{D}}\right)^{\frac{1}{1-\alpha}}\right] & -\frac{\beta_{D}}{\gamma_{D} \phi} E_{t+1}+b_{D t+1}+b_{F t+1} \\
& =\frac{\beta_{F}}{1+\beta_{F}}\left[(1-\alpha) A_{F} k_{D t}^{\alpha}\left(\frac{A_{F}}{A_{D}}\right)^{\frac{\alpha}{1-\alpha}}-\tau_{F t}\right]
\end{aligned}
$$

Substituting (2), (10), (17) and $a_{F t}=0$, equation (16) becomes:

$$
\left(1+\frac{1+\beta_{D}}{\gamma_{D}}\right) E_{t+1}=E_{t}-\phi \tau_{D t}+A_{D} k_{D t}^{\alpha}\left[\phi(1-\alpha)-\theta\left(1+\left(\frac{A_{F}}{A_{D}}\right)^{\frac{1}{1-\alpha}}\right)\right]
$$

An equilibrium with $a_{D t}>0$ and $a_{F t}=0$ satisfies equations (20) and (21), taking into account that inequalities (19) hold and the government budget constraint is given by (18).

\subsection{Equilibrium with $a_{D t}>0$ and $a_{F t}>0$}

Using inequality (12), we deduce that $a_{D t}>0$ and $a_{F t}>0$ require:

$$
E_{t+1}<\phi \min \left\{\frac{\gamma_{D}}{1+\beta_{D}}\left[(1-\alpha) A_{D} k_{D t}^{\alpha}-\tau_{D t}\right] ; \frac{\gamma_{F}}{1+\beta_{F}}\left[(1-\alpha) A_{F} k_{D t}^{\alpha}\left(\frac{A_{F}}{A_{D}}\right)^{\frac{\alpha}{1-\alpha}}-\tau_{F t}\right]\right\}
$$

Using (9) and (17), the equilibrium condition (15) rewrites:

$$
\frac{1}{\phi} E_{t+1}\left(\frac{\beta_{D}}{\gamma_{D}}+\frac{\beta_{F}}{\gamma_{F}}\right)=k_{D t+1}\left[1+\left(\frac{A_{F}}{A_{D}}\right)^{\frac{1}{1-\alpha}}\right]+b_{D t+1}+b_{F t+1}
$$


Now, using (2), (10) and (17), the dynamics of environmental quality (16) becomes:

$$
\begin{aligned}
& \left(1+\frac{1+\beta_{D}}{\gamma_{D}}+\frac{1+\beta_{F}}{\gamma_{F}}\right) E_{t+1}=E_{t}-\phi\left(\tau_{D t}+\tau_{F t}\right) \\
& +A_{D} k_{D t}^{\alpha}[\phi(1-\alpha)-\theta]\left[1+\left(\frac{A_{F}}{A_{D}}\right)^{\frac{1}{1-\alpha}}\right]
\end{aligned}
$$

An equilibrium with $a_{D t}>0$ and $a_{F t}>0$ satisfies equations (23) and (24), taking into account the government budget constraint (18) and inequalities (22).

\section{A foreign economy with low environmental sensitivity $\left(\gamma_{F}\right.$ ar- bitrarily small)}

We consider first a foreign economy with green awareness lower than in the domestic economy, and even arbitrarily small and close to zero.

Assumption $2 \gamma_{F}$ arbitrarily small, satisfying $\gamma_{F}<\gamma_{D}$, and close to 0 .

Substituting (18) in (19), the economy is in the asymmetric case $a_{D t}>0$ and $a_{F t}=0$ if the following inequalities are satisfied:

$$
\begin{aligned}
& E_{t+1}<\frac{\phi \gamma_{D}}{1+\beta_{D}}\left[(1-\alpha) A_{D} k_{D t}^{\alpha}-b_{D}\left(\alpha A_{D} k_{D t}^{\alpha-1}-1\right)\right] \\
& E_{t+1}>\frac{\phi \gamma_{F}}{1+\beta_{F}}\left[(1-\alpha) A_{D} k_{D t}^{\alpha}\left(\frac{A_{F}}{A_{D}}\right)^{\frac{1}{1-\alpha}}-b_{F}\left(\alpha A_{D} k_{D t}^{\alpha-1}-1\right)\right]
\end{aligned}
$$

Under Assumption 2, we note that any steady state $\left(k_{D}, E\right)$ will satisfy equation (26), meaning that there will be no steady state with $a_{F}>0$ when $\gamma_{F}$ is small and close to zero. This leads us to restrict our attention to equilibria such that $a_{D t}>0$ and $a_{F t}=0$ when Assumption 2 is satisfied.

\subsection{Dynamics and steady states}

Substituting (18) in equations (20) and (21), we obtain the dynamic behavior of the model:

$$
\begin{aligned}
& k_{D t+1}\left[1+\left(\frac{A_{F}}{A_{D}}\right)^{\frac{1}{1-\alpha}}\right]-\frac{\beta_{D}}{\gamma_{D} \phi} E_{t+1}+b_{D}+\frac{b_{F}}{1+\beta_{F}} \\
& =\frac{\beta_{F}}{1+\beta_{F}}\left[(1-\alpha) A_{F} k_{D t}^{\alpha}\left(\frac{A_{F}}{A_{D}}\right)^{\frac{\alpha}{1-\alpha}}-b_{F} \alpha A_{D} k_{D t}^{\alpha-1}\right] \\
& \left(1+\frac{1+\beta_{D}}{\gamma_{D}}\right) E_{t+1}=E_{t}-\phi b_{D}\left[\alpha A_{D} k_{D t}^{\alpha-1}-1\right] \\
& +A_{D} k_{D t}^{\alpha}\left[\phi(1-\alpha)-\theta\left(1+\left(\frac{A_{F}}{A_{D}}\right)^{\frac{1}{1-\alpha}}\right)\right]
\end{aligned}
$$


Substituting (28) into (27), we get:

$$
\begin{aligned}
& k_{D t+1}\left[1+\left(\frac{A_{F}}{A_{D}}\right)^{\frac{1}{1-\alpha}}\right]=-\frac{b_{D}\left(1+\gamma_{D}\right)}{1+\beta_{D}+\gamma_{D}}-\frac{b_{F}}{1+\beta_{F}}+\frac{\beta_{D}}{1+\beta_{D}+\gamma_{D}} \frac{E_{t}}{\phi} \\
& +k_{D t}^{\alpha}\left[(1-\alpha) A_{F}\left(\frac{A_{F}}{A_{D}}\right)^{\frac{\alpha}{1-\alpha}} \frac{\beta_{F}}{1+\beta_{F}}+A_{D}\left(1-\alpha-\frac{\theta}{\phi}\left(1+\left(\frac{A_{F}}{A_{D}}\right)^{\frac{1}{1-\alpha}}\right)\right) \frac{\beta_{D}}{1+\beta_{D}+\gamma_{D}}\right] \\
& -\alpha A_{F} k_{D t}^{\alpha-1}\left[\frac{b_{F} \beta_{F}}{1+\beta_{F}}+\frac{b_{D} \beta_{D}}{1+\beta_{D}+\gamma_{D}}\right]
\end{aligned}
$$

The dynamic system (28) and (29) explicitly gives $\left(E_{t+1}, k_{D t+1}\right)$ as functions of $\left(E_{t}, k_{D t}\right)$. Now, we use it to analyse the existence and the number of steady states, and their stability properties.

Using (28), we deduce that $E_{t+1} \geqslant E_{t}$ if and only if:

$$
\begin{aligned}
& E_{t} \leqslant \varphi\left(k_{D t}\right) \equiv \\
& \left\{A_{D} k_{D t}^{\alpha}\left[\phi(1-\alpha)-\theta\left(1+\left(\frac{A_{F}}{A_{D}}\right)^{\frac{1}{1-\alpha}}\right)\right]-\phi b_{D}\left[\alpha A_{D} k_{D t}^{\alpha-1}-1\right]\right\} \frac{\gamma_{D}}{1+\beta_{D}}
\end{aligned}
$$

To be able to ensure $E_{t}>0$ even if there is under-accumulation of capital $\left(\alpha A_{D} k_{D t}^{\alpha-1}>1\right)$, we assume:

Assumption $3 \phi(1-\alpha)>\theta\left(1+\left(\frac{A_{F}}{A_{D}}\right)^{\frac{1}{1-\alpha}}\right)$.

This assumption can be easily interpreted. Indeed, it can be rewritten as $\phi w_{D}>\theta\left(y_{D}+y_{F}\right)$ meaning that when the rich country spends all its income on mitigation, it has to absorb more than the total flow of pollution. This is empirically relevant because when the domestic advanced economy does not save, capital is only financed by the poorest economy, meaning that the capital stock and hence the pollution flow are low.

Using now (29), the inequality $k_{D t+1} \geqslant k_{D t}$ is equivalent to $E_{t} \geqslant \psi\left(k_{D t}\right)$, with:

$$
\begin{aligned}
& \frac{\beta_{D}}{1+\beta_{D}+\gamma_{D}} \frac{1}{\phi} \psi\left(k_{D t}\right)=k_{D t}\left[1+\left(\frac{A_{F}}{A_{D}}\right)^{\frac{1}{1-\alpha}}\right]+\frac{b_{D}\left(1+\gamma_{D}\right)}{1+\beta_{D}+\gamma_{D}}+\frac{b_{F}}{1+\beta_{F}} \\
& -k_{D t}^{\alpha}\left[(1-\alpha) A_{F}\left(\frac{A_{F}}{A_{D}}\right)^{\frac{\alpha}{1-\alpha}} \frac{\beta_{F}}{1+\beta_{F}}+A_{D}\left(1-\alpha-\frac{\theta}{\phi}\left(1+\left(\frac{A_{F}}{A_{D}}\right)^{\frac{1}{1-\alpha}}\right)\right) \frac{\beta_{D}}{1+\beta_{D}+\gamma_{D}}\right] \\
& +\alpha A_{F} k_{D t}^{\alpha-1}\left[\frac{b_{F} \beta_{F}}{1+\beta_{F}}+\frac{b_{D} \beta_{D}}{1+\beta_{D}+\gamma_{D}}\right]
\end{aligned}
$$

We note that $\varphi\left(k_{D t}\right)$ is increasing and concave, while $\psi\left(k_{D t}\right)$ is U-shaped. Now, using (28), 
inequalities (25) and (26) are equivalent to:

$$
\begin{aligned}
& E_{t}<A_{D} k_{D t}^{\alpha}\left[\frac{\phi \gamma_{D}}{1+\beta_{D}}(1-\alpha)+\theta\left(1+\left(\frac{A_{F}}{A_{D}}\right)^{\frac{1}{1-\alpha}}\right)\right]-\left(\alpha A_{D} k_{D t}^{\alpha-1}-1\right) \frac{\phi \gamma_{D} b_{D}}{1+\beta_{D}} \equiv C_{D}\left(k_{D t}\right) \\
& E_{t}>-A_{D} k_{D t}^{\alpha}\left[\phi(1-\alpha)\left(1-\left(\frac{A_{F}}{A_{D}}\right)^{\frac{1}{1-\alpha}} \frac{\left(1+\beta_{D}+\gamma_{D}\right) \gamma_{F}}{\left(1+\beta_{F}\right) \gamma_{D}}\right)-\theta\left(1+\left(\frac{A_{F}}{A_{D}}\right)^{\frac{1}{1-\alpha}}\right)\right] \\
& +\left(\alpha A_{D} k_{D t}^{\alpha-1}-1\right) \phi\left[b_{D}-b_{F} \frac{\left(1+\beta_{D}+\gamma_{D}\right) \gamma_{F}}{\left(1+\beta_{F}\right) \gamma_{D}}\right] \equiv C_{F}\left(k_{D t}\right)
\end{aligned}
$$

where $C_{D}\left(k_{D t}\right)$ is increasing and concave and $C_{F}\left(k_{D t}\right)$ is decreasing and convex. Moreover, $C_{D}\left(k_{D t}\right)>\varphi\left(k_{D t}\right)$ for all $k_{D t}>0$, which means that a steady state satisfies $a_{D}>0$ whatever the value of $k_{D}$. As shown in Appendix 7.1, there is $\underline{k}>0$ such that for all $k_{D t}>\underline{k}$, we have $C_{D}\left(k_{D t}\right)>\varphi\left(k_{D t}\right)>C_{F}\left(k_{D t}\right)$. We also show whether $\psi\left(k_{D t}\right) \geqslant C_{F}\left(k_{D t}\right)$. See Figure 1 for a representation.

To complete the picture, a steady state is of course a solution $\left(E_{t}, k_{D t}\right)=\left(E_{t+1}, k_{D t+1}\right)=$ $\left(E, k_{D}\right)$ satisfying equations $(27)$ and $(28)$, which corresponds to the intersections between $\varphi\left(k_{D t}\right)$ and $\psi\left(k_{D t}\right)$. This allows us to deduce the number of steady states depending on the importance of the policy parameters $b_{D}$ and $b_{F}$ (see also Figure 1 for the case with two steady states):

Proposition 1 Under Assumptions 1-3, there exist two steady states with $a_{D}>0$ and $a_{F}=0$, namely $\left(k_{j}, E_{j}\right)$ with $j=\{l, h\}$ and $0<k_{l}<k_{h}$, if public debt (at least in one country) is positive, with $b_{D}$ and $b_{F}$ low enough. If public debt (in one or the two countries) is too large, there is no steady state with $a_{D}>0$ and $a_{F}=0$.

If we further assume that:

$$
\frac{\alpha}{1-\alpha}>\frac{\frac{\beta_{D}}{1+\beta_{D}}+\frac{\beta_{F}}{1+\beta_{F}}\left(\frac{A_{F}}{A_{D}}\right)^{\frac{1}{1-\alpha}}}{1+\left(\frac{A_{F}}{A_{D}}\right)^{\frac{1}{1-\alpha}}}
$$

the two existing steady states are characterized by under-accumulation.

Proof. See Appendix 7.2

Proposition 1 shows that there are two steady states with $a_{D}>0$ and $a_{F}=0$ when the public debt in both countries is positive but not too high. This is a common feature of dynamic models with a constant level of public debt, including those with pollution (see Fodha and Seegmuller 2012, 2014). Using the ingredients of this section and Appendix 7.1, we can also deduce the stability properties of the steady states, drawing the phase diagram as depicted in Figure 1. The steady state with the highest level of capital is stable, whereas the one with the lowest level of capital is a saddle. Given that there are two predetermined variables, this last one is generically unstable. 


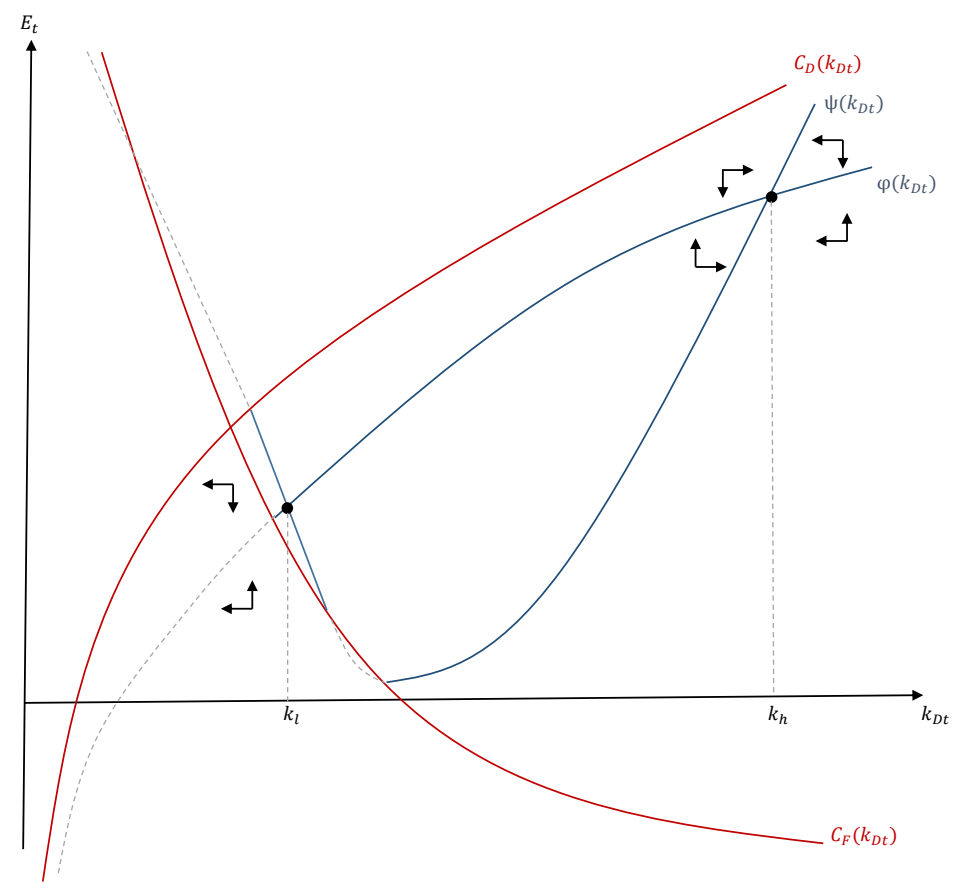

Figure 1 - Global dynamics under $\gamma_{F}$ arbitrarily small.

As generations overlap, agents may over- or under-accumulate capital relatively to the usual golden rule. The sufficient condition to have under-accumulation seems to be quite standard since it requires that capital income over labor income has to be higher than a weighted sum of the saving rates $\beta_{i} /\left(1+\beta_{i}\right)$. Under-accumulation ensures in particular that the tax levels $\tau_{i}=b_{i}\left(\alpha A_{i} k_{i}^{\alpha-1}-1\right)$, for $i=D, F$, are positive as gouvernements are indebted.

\subsection{Policy implications}

This section explores how capital, environmental quality and the welfare of consumers could be affected by changes of the level of public debt in both countries. More precisely, we examine the effect of a bilateral debt relief in favor of the less advanced country i.e. the foreign one $i=F$. We can justify this policy scheme using two arguments. First, the debt burden in poorest countries can act as a brake on development, and richest countries must express support to relax this constraint. Second, for fairness motives: the biggest contributor to climate change are richmore technological advanced- countries. This is consistent with the concept of climate justice promoted by United Nations (2009): ‘[... the world's richest countries have contributed most to the problem, they have a greater obligation to take action and to do so more quickly."

Considering that Proposition 1 holds, we investigate the effect of a debt transfer, i.e. an increase of $b_{D}$ associated to a decrease of $b_{F}$ of the same amount, on the stationary stock of 
capital and on the environment. ${ }^{4}$ Examining the government budget constraint given by (18), a debt transfer directly translates into a variation of disposable income, positive for the country that receives the transfer and negative for the contributor.

These comparative statics are evaluated at the steady state with the highest level of capital, since it is the only one stable.

Proposition 2 Under Assumptions 1-3, $b_{D}$ and $b_{F}$ not too high and inequality (34):

- When the domestic economy is more patient that the foreign one, $\beta_{D}>\beta_{F}$, an increase of $b_{D}$ associated to a decrease of $b_{F}$ of the same amount reduces $E_{h}$ and $k_{h}$.

- When the domestic economy is less patient that the foreign one, $\beta_{D}<\beta_{F}$, an increase of $b_{D}$ associated to a decrease of $b_{F}$ of the same amount increases $k_{h}$, and $E_{h}$ if ${ }^{5}$ :

$$
\frac{\beta_{F}}{1+\beta_{F}}-\frac{\beta_{D}}{1+\beta_{D}}>\frac{1}{b_{D} \mathcal{X}}
$$

Proof. See Appendix 7.3

We first discuss the effect of the debt transfer on the level of capital. To understand the economic mechanism, we recall the expressions of the savings in the two countries. Using (9) and (10) on the one hand, and (11) on the other hand, we have:

$$
\begin{aligned}
& s_{D}=\frac{\beta_{D}}{1+\beta_{D}}\left(w_{D}-\tau_{D}-a_{D}\right), \\
& s_{F}=\frac{\beta_{F}}{1+\beta_{F}}\left(w_{F}-\tau_{F}\right)
\end{aligned}
$$

In addition, the equilibrium conditions (15) and (16) evaluated at a steady state can be written:

$$
\begin{aligned}
s_{D}+s_{F} & =k_{D}\left[1+\left(\frac{A_{F}}{A_{D}}\right)^{\frac{1}{1-\alpha}}\right]+b_{D}+b_{F}, \\
a_{D} & =\frac{\theta}{\phi} A_{D} k_{D}^{\alpha}\left[1+\left(\frac{A_{F}}{A_{D}}\right)^{\frac{1}{1-\alpha}}\right]
\end{aligned}
$$

The increase of the public debt in the domestic economy means a larger taxation. We observe the reverse mechanism in the foreign economy, where the level of public debt goes down. Debt transfer entails a fall of savings in the domestic economy and an increase in the foreign one, while the aggregate level of debt $b_{D}+b_{F}$ is unchanged. The effect on global savings depends on differences in time preferences, i.e $\beta_{D}$ compare to $\beta_{F}$, which determine the saving rates in the two countries. When $\beta_{D}>\beta_{F}$, the domestic economy is more patient, global savings go down, and, given the perfect capital mobility, so does the stock of capital. We get the reverse result when

\footnotetext{
${ }^{4}$ Note that we would get the reverse result following an increase of $b_{F}$ associated to a decrease of $b_{D}$.

${ }^{5}$ The expression for $\mathcal{X}$ is given in Appendix 7.3.
} 
$\beta_{D}<\beta_{F}$. This is due to a redistribution of net income from country $\mathrm{D}$ to country $\mathrm{F}$. At a steady state, environmental preferences do not modify this conclusion, even if savings in the domestic economy depend on the environmental quality. As it is clear from equation (39), abatement along the steady sate exactly compensates pollution flows coming from aggregate production. Because of perfect mobility of assets, this implies that abatement is determined by the level of capital and not the distribution of income.

Then, we emphasize the effects on the environmental quality. A policy that leads economies to a state with a lower stock of capital reduces labor income and the environmental contribution of the domestic economy. Given the efficiency of abatement compare to the polluting intensity of production (Assumption 3), a fall in capital stock damages the environment. This is why a debt transfer from the domestic to the foreign economy damages environmental quality when $\beta_{D}>\beta_{F}$. When the foreign economy is more patient $\left(\beta_{D}<\beta_{F}\right)$, an additional condition is required to ensure that a debt transfer from the domestic to the foreign economy is efficient to improve the environment. Indeed, the domestic economy is the only contributor to environmental protection and a policy aiming at increase its debt level would entail direct negative income effect, with adverse consequences on abatement activities. The condition (35) presented in Proposition 2 implies that the elasticity of the capital stock to debt variation is sufficiently high to overtake the direct negative effect of debt variation on abatement spendings through the variation of taxes. ${ }^{6}$ It especially requires a significant difference between $\beta_{F}$ and $\beta_{D}$ to ensure, following the debt transfer, a high enough increase of global savings and, therefore, capital.

We investigate now the welfare effects of the debt transfer. Debt policy affects welfare though its impact on the environment and on consumption spendings. The consumption part of the welfare is affected by debt transfer through three effects: First, a direct debt effect, because any variation in the level of debt changes the tax on income; Second, an income effect because the variation of capital stock entailed by the policy modifies the return on labor and on capital; Finally, a cost of debt effect because of the variation in the interest rate and hence of the country's debt burden. These effects can be competing. The welfare analysis is presented in the following proposition:

Proposition 3 Under Assumptions 1-3, $b_{D}$ and $b_{F}$ not too high, and $\alpha /(1-\alpha)>\max \left\{\frac{\beta_{D}}{1+\beta_{D}} ; \frac{\beta_{F}}{1+\beta_{F}}\right\}$, we have the following results:

- For $\beta_{D}>\beta_{F}$, an increase of $b_{D}$ associated to a decrease of $b_{F}$ of the same amount reduces the welfare in the domestic country while the impact is ambiguous for the foreign one.

- For $\beta_{D}<\beta_{F}$ and under condition (35), an increase of $b_{D}$ associated to a decrease of $b_{F}$ of the same amount increases the welfare in the foreign country while the impact is ambiguous for the domestic one.

\footnotetext{
${ }^{6}$ For more details, see Appendix 7.3.
} 
Proof. See Appendix 7.4

When the foreign economy is impatient relative to the domestic one, a debt transfer in its favor leads economies to converge to a lower stock of capital and to a worsen environmental quality. Nevertheless, if the debt reduction is sufficiently high, these negative effects could, at least partially, be compensated in the foreign country by the direct increase in consumption spendings associated to a higher after-tax income.

The result is different if the foreign economy is relatively more patient and the variation of the capital stock with respect to debt is sufficiency high to ensure that it drives an improvement of the environmental quality. In such a situation, welfare improves in the foreign economy, while the impact remains unclear for the welfare of the domestic economy because it suffers from an increase in its debt. If it is highly sensitive to climate change issue ( $\gamma_{D}$ high enough), the better environmental quality could a priori compensate the increase of tax burden.

We emphasize in this section that when the poorest economy is characterized by low environmental concern $\left(\gamma_{F}\right.$ is arbitrarily small), the two steady states are always characterized by the same configuration, i.e. domestic country contributes to environmental protection while the foreign economy does not. As long as green awareness of foreign agents is too low, a debt transfer from the domestic to the foreign economy is not an efficient policy tool to induce them to contribute to the environment. Moreover, it reduces capital stock and environmental quality if the richest economy is more patient. On the contrary, if the advanced economy is less patient, such a transfer allows to converge to a higher stock of capital and to a better environmental quality. In such a configuration, the debt relief is an efficient policy even if the poor country remains not engaged in mitigation.

\section{A foreign economy with a significant environmental sensitivity $\left(\gamma_{F}\right.$ significant $)$}

Now, households living in the foreign country are significantly concerned by environmental quality, i.e. the preference parameter $\gamma_{F}$ is no more arbitrarily small. We will highlight the policy implications it will imply in comparison with the previous case. We especially emphasize some configurations where debt transfers between the two countries may induce significant changes in the private engagement concerning environmental mitigation. To be more specific, we assume:

Assumption $4 \gamma_{F}$ is high enough, satisfying the following inequality:

$$
\frac{\gamma_{F}}{1+\beta_{F}}>\max \left\{\left(\frac{A_{D}}{A_{F}}\right)^{\frac{1}{1-\alpha}} ; \frac{b_{D}}{b_{F}}\right\} \frac{\gamma_{D}}{1+\beta_{D}}
$$

By inspection of equation (32), we observe that the frontier defining whether $a_{D t}$ is positive or not, namely $E_{t}=C_{D}\left(k_{D t}\right)$, is not affected by $\gamma_{F}$. Therefore, it has the same properties than 
in Section 4. However, under Assumption 4, $E_{t}=C_{F}\left(k_{D t}\right)$, defined in equation (33) and such that $a_{F t}=0$, becomes an increasing and concave function. ${ }^{7}$ We will see that this will have strong implications on the existence of steady states and on the effectiveness of policies making some transfers of debt between the two countries.

We start by investigating the region where $a_{D t}>0$ and $a_{F t}>0$, which becomes relevant because $\gamma_{F}$ is high enough. We focus on the existence of steady states, their stability properties and the effectiveness of debt transfers keeping $b_{D}+b_{F}$ constant. Then, we will investigate whether debt transfers allow to promote abatements in country $F$ at the stable steady state with the highest level of capital. We will analyze the consequences of such policies on capital, environmental quality and welfare.

\subsection{The regime with $a_{D t}>0$ and $a_{F t}>0$}

Under Assumption 4, we study equilibria where both countries are engaging in abatements. Using (18), equations (23) and (24) rewrite:

$$
\begin{aligned}
& \frac{1}{\phi} E_{t+1}\left(\frac{\beta_{D}}{\gamma_{D}}+\frac{\beta_{F}}{\gamma_{F}}\right)=k_{D t+1}\left[1+\left(\frac{A_{F}}{A_{D}}\right)^{\frac{1}{1-\alpha}}\right]+b_{D}+b_{F} \\
& \left(1+\frac{1+\beta_{D}}{\gamma_{D}}+\frac{1+\beta_{F}}{\gamma_{F}}\right) E_{t+1}=E_{t}-\phi\left(b_{D}+b_{F}\right)\left[\alpha A_{D} k_{D t}^{\alpha-1}-1\right] \\
& +A_{D} k_{D t}^{\alpha}[\phi(1-\alpha)-\theta]\left[1+\left(\frac{A_{F}}{A_{D}}\right)^{\frac{1}{1-\alpha}}\right]
\end{aligned}
$$

Equation (41) gives the dynamics of environmental quality, whereas equation (40) gives a static link between $E_{t}$ and $k_{D t}$. Using (41), $E_{t+1} \geqslant E_{t}$ if and only if $E_{t} \leqslant \Omega\left(k_{D t}\right)$, with:

$$
\begin{aligned}
& \left(\frac{1+\beta_{D}}{\gamma_{D}}+\frac{1+\beta_{F}}{\gamma_{F}}\right) \Omega\left(k_{D t}\right)=-\phi\left(b_{D}+b_{F}\right)\left[\alpha A_{D} k_{D t}^{\alpha-1}-1\right] \\
& +A_{D} k_{D t}^{\alpha}[\phi(1-\alpha)-\theta]\left[1+\left(\frac{A_{F}}{A_{D}}\right)^{\frac{1}{1-\alpha}}\right]
\end{aligned}
$$

where $\Omega\left(k_{D t}\right)$ is strictly increasing and concave under Assumption 3. Substituting (41) into (40), $k_{D t+1} \geqslant k_{D t}$ is equivalent to $E_{t} \geqslant \Pi\left(k_{D t}\right)$, with:

$$
\begin{aligned}
\Pi\left(k_{D t}\right) \equiv & \phi \frac{\gamma_{D} \gamma_{F}+\gamma_{F}\left(1+\beta_{D}\right)+\gamma_{D}\left(1+\beta_{F}\right)}{\gamma_{F} \beta_{D}+\gamma_{D} \beta_{F}}\left[k_{D t}\left(1+\left(\frac{A_{F}}{A_{D}}\right)^{\frac{1}{1-\alpha}}\right)+b_{D}+b_{F}\right] \\
& +\phi\left(b_{D}+b_{F}\right)\left(\alpha A_{D} k_{D t}^{\alpha-1}-1\right)-A_{D} k_{D t}^{\alpha}[\phi(1-\alpha)-\theta]\left[1+\left(\frac{A_{F}}{A_{D}}\right)^{\frac{1}{1-\alpha}}\right]
\end{aligned}
$$

where $\Pi\left(k_{D t}\right)$ is a U-shaped function. Of course, all dynamic trajectory $\left(k_{D t}, E_{t}\right)$ with $a_{D t}>0$ and $a_{F t}>0$ should satisfy $E_{t}<\min \left\{C_{F}\left(k_{D t}\right), C_{D}\left(k_{D t}\right)\right\}$.

\footnotetext{
${ }^{7}$ We will also have $\lim _{k_{D t} \rightarrow 0} C_{F}\left(k_{D t}\right)=-\infty$ and $\lim _{k_{D t} \rightarrow+\infty} C_{F}\left(k_{D t}\right)=+\infty$.
} 
We examine now if some long term steady states in which both countries contribute to environmental protection may exist. To this aim, we analyze if positive abatement activities in the foreign and the domestic good are compatible with a stationary stock of capital and a constant value of environmental index.

Proposition 4 Under Assumptions 1, 3 and 4, there exist two steady states with $a_{D}>0$ and $a_{F}>0$, namely $\left(k_{j}^{s}, E_{j}^{s}\right)$ with $j=\{l, h\}$ and $0<k_{l}^{s}<k_{h}^{s}$, if public debt (at least in one country) is positive, with $b_{D}$ and $b_{F}$ low enough. If public debt (in one or the two countries) is too large, there is no steady states with $a_{D}>0$ and $a_{F}>0$.

These steady states are admissible if $E_{j}^{s}<\min \left\{C_{F}\left(k_{j}^{s}\right), C_{D}\left(k_{j}^{s}\right)\right\}$ is satisfied. If we further assume that:

$$
\phi(1-\alpha)-\theta<\alpha \frac{\left(1+\beta_{D}\right) \gamma_{F}+\left(1+\beta_{F}\right) \gamma_{D}}{\gamma_{F} \beta_{D}+\gamma_{D} \beta_{F}}
$$

they are characterized by under-accumulation.

Proof. See Appendix 7.6

Note that the conditions for the existence of two steady states when $a_{D}>0$ and $a_{F}>0$ is closely related to what happens when $a_{D}>0$ and $a_{F}=0$. In both cases, the debt levels should be positive but not too high. Therefore, the question will be whether the steady states in each regime are admissible or not, i.e. really satisfy $a_{F}>0$ or $a_{F}=0$ respectively. We also remark that the sufficient condition to have under-accumulation is compatible with Assumption 3, for an appropriate level of $\phi$, if $\alpha \frac{\left(1+\beta_{D}\right) \gamma_{F}+\left(1+\beta_{F}\right) \gamma_{D}}{\gamma_{F} \beta_{D}+\gamma_{D} \beta_{F}}>\theta\left(A_{F} / A_{D}\right)^{\frac{1}{1-\alpha}}$, which is for instance satisfied for $\theta$ low enough.

All the ingredients of this section also allow to deduce the dynamics when $a_{D t}>0$ and $a_{F t}>0$ showing that the steady state with the highest level of capital is stable, whereas the other one is a saddle.

We can investigate the effects of public debt transfer when both countries contribute to the environmental protection.

Proposition 5 Under Assumptions 1, 3 and 4, assume that $b_{D}$ and $b_{F}$ are low enough. Any increase of $b_{D}$ associated to a decrease of $b_{F}$ of the same amount has no effect on an equilibrium with $a_{D t}>0$ and $a_{F t}>0$.

When both countries invest to improve environmental quality, a transfer of debt from the domestic to the foreign country that let the total amount of debt $b_{D}+b_{F}$ unchanged is useless. By inspection of the equilibrium conditions (40) and (41), it does not modify any dynamic trajectory characterized by $a_{D t}>0$ and $a_{F t}>0$. 
Using (9), (10), (15) and (16), the equilibrium conditions can be written:

$$
\begin{aligned}
& s_{D t}+s_{F t}=k_{D t+1}\left(1+\left(\frac{A_{F}}{A_{D}}\right)^{\frac{1}{1-\alpha}}\right)+b_{D}+b_{F} \\
& E_{t+1}=E_{t}-\theta A_{D} k_{D t}^{\alpha}\left(1+\left(\frac{A_{F}}{A_{D}}\right)^{\frac{1}{1-\alpha}}\right)+\phi\left(a_{D t}+a_{F t}\right)
\end{aligned}
$$

where $s_{i t}$ and $a_{i t}$ are given by (9) and (10). Since $s_{i t}$ can be expressed as functions of environmental quality, aggregate savings do not depend on the distribution of income across countries. Therefore, this heterogeneity of incomes between countries $D$ and $F$ has no effect on the asset equilibrium, i.e. on capital. By inspection of (10), abatement linearly depends on income. Since the efficiency of abatement on environmental quality $\phi$ is the same in both countries, the distribution of income has also no effect on environmental quality.

\subsection{The interplay between debt and the existence of steady states with envi- ronmental mitigation}

We investigate now if a policy consisting in debt transfers can promote the environmental maintenance of the foreign economy, moving from an equilibrium with $a_{F t}=0$ to an equilibrium with positive abatement $a_{F t}>0$. The underlying question is of course to know whether such a policy is relevant to improve capital, environmental quality and welfare in a globalized world.

To be more specific, we will start with a configuration where there exist two steady states with $a_{D}>0$ and $a_{F}=0$. Then, we will show that a debt transfer among countries will lead to a configuration where the stable steady state with the highest level of capital moves from a situation where $a_{D}>0$ and $a_{F}=0$ to a situation where $a_{D}>0$ and $a_{F}>0$. We will investigate what are the implications of such a change of regime on capital, environmental quality and welfare.

Our explanations are based on phase diagrams, represented in Figures 2 and 3, which allows to have a global picture of the existence of steady states and dynamics. We start by focusing on equilibria with $a_{D t}>0$ and $a_{F t}=0$ when $\gamma_{F}$ satisfies Assumption 4 and highlight the differences with the previous case where $\gamma_{F}$ is arbitrarily low. By inspection of equations (30)-(32), we observe that $\varphi\left(k_{D t}\right), \psi\left(k_{D t}\right)$ and $C_{D}\left(k_{D t}\right)$ are not affected by $\gamma_{F}$, meaning that they have the same properties than in Section 4 . To locate these curves in the $\left(k_{D t}, E_{t}\right)$ plane, especially with respect to $C_{D}\left(k_{D t}\right)$ and $C_{F}\left(k_{D t}\right)$, we further assume:

\section{Assumption 5}

$$
\frac{b_{D}}{b_{F}}<\frac{\phi(1-\alpha)-\theta\left(1+\left(\frac{A_{F}}{A_{D}}\right)^{\frac{1}{1-\alpha}}\right)}{\phi(1-\alpha)\left(\frac{A_{F}}{A_{D}}\right)^{\frac{1}{1-\alpha}}} \equiv\left(\frac{b_{D}}{b_{F}}\right)^{+}
$$

This assumption implies that $b_{D} / b_{F}<\left(A_{D} / A_{F}\right)^{\frac{1}{1-\alpha}}$, meaning that the debt per GDP in 
advanced country, $b_{D} / A_{D}^{\frac{1}{1-\alpha}}$, is lower than in foreign country, $b_{F} / A_{F}^{\frac{1}{1-\alpha}} \cdot 8$

As shown in Appendix 7.5, where some technical details to construct the phase diagram when $\gamma_{F}$ is significant are relegated, we note that, on the one hand, $\varphi\left(k_{D t}\right)$ and $\Omega\left(k_{D t}\right)$, that correspond to $E_{t+1}=E_{t}$, are both increasing and concave functions and cross the curve $C_{F}\left(k_{D t}\right)$ at the same point given by $k_{D t}=k_{1}$. Moreover, $\varphi\left(k_{D t}\right)>0$ for $k_{D t}>k_{0}, \varphi\left(k_{D t}\right)$ is above $C_{F}\left(k_{D t}\right)$ for $k_{D t} \leqslant k_{1}$ and $\Omega\left(k_{D t}\right)$ is below $C_{F}\left(k_{D t}\right)$ for $k_{D t} \geqslant k_{1}$, where $k_{1}>k_{0}$ under Assumption 5. On the other hand, $\psi\left(k_{D t}\right)$ and $\Pi\left(k_{D t}\right)$, that correspond to $k_{D t+1}=k_{D t}$, are both convex U-shaped functions that cross the curve $C_{F}\left(k_{D t}\right)$ at the same points. We denote $k_{D t}=k_{a}$ and $k_{D t}=k_{b}$, with $k_{a}>k_{b}$ these two points.

Using the constraint (26), a steady state with $a_{D}>0$ and $a_{F}=0$ requires $^{9}$ :

$$
E>\frac{\phi \gamma_{F}}{1+\beta_{F}}\left[(1-\alpha) A_{D} k_{D}^{\alpha}\left(\frac{A_{F}}{A_{D}}\right)^{\frac{1}{1-\alpha}}-b_{F}\left(\alpha A_{D} k_{D}^{\alpha-1}-1\right)\right]
$$

Using (28), such a steady state should satisfy $\Theta\left(k_{D}\right)<0$, with:

$$
\begin{aligned}
\Theta\left(k_{D}\right) \equiv & A_{D} k_{D}^{\alpha}\left[(1-\alpha)\left(\frac{\gamma_{F}}{1+\beta_{F}}\left(\frac{A_{F}}{A_{D}}\right)^{\frac{1}{1-\alpha}}-\frac{\gamma_{D}}{1+\beta_{D}}\right)+\frac{\gamma_{D}}{1+\beta_{D}} \frac{\theta}{\phi}\left(1+\left(\frac{A_{F}}{A_{D}}\right)^{\frac{1}{1-\alpha}}\right)\right] \\
& +\left(\alpha A_{D} k_{D}^{\alpha-1}-1\right)\left(\frac{\gamma_{D} b_{D}}{1+\beta_{D}}-\frac{\gamma_{F} b_{F}}{1+\beta_{F}}\right)
\end{aligned}
$$

where $\Theta\left(k_{D}\right)$ is an increasing function under Assumption 4. Of course, a steady state with $a_{D}>0$ and $a_{F}>0$ requires the opposite inequality, i.e. $\Theta\left(k_{D}\right)>0$.

Using Appendices 7.2 and 7.6, there exist $\widehat{k}$ and $\widehat{k}^{s}$ such that the possible steady states $k_{l}$ and $k_{h}$ with $a_{F}=0$ and $a_{D}>0$ are such that $k_{l}<k_{h}<\widehat{k}$ and the possible steady states $k_{l}^{s}$ and $k_{h}^{s}$ with $a_{F}>0$ and $a_{D}>0$ are such that $k_{l}^{s}<k_{h}^{s}<\widehat{k}^{s}$.

Therefore, only the steady states $k_{l}$ and $k_{h}$ exist if $\Theta\left(\widehat{k}^{s}\right)<0$ and $\Theta(\widehat{k})<0$. Let:

$$
\Sigma \equiv \frac{\gamma_{F} b_{F}}{1+\beta_{F}}-\frac{\gamma_{D} b_{D}}{1+\beta_{D}}
$$

These two inequalities are equivalent to $\Sigma>\Sigma_{0}$ and $\Sigma>\Sigma_{1}$, with:

$$
\begin{aligned}
& \Sigma_{0} \equiv \frac{A_{D}\left(\frac{J_{1}}{J_{2}}\right)^{\frac{\alpha}{1-\alpha}}\left[(1-\alpha)\left(\frac{\gamma_{F}}{1+\beta_{F}}\left(\frac{A_{F}}{A_{D}}\right)^{\frac{1}{1-\alpha}}-\frac{\gamma_{D}}{1+\beta_{D}}\right)+\frac{\gamma_{D}}{1+\beta_{D}} \frac{\theta}{\phi}\left(1+\left(\frac{A_{F}}{A_{D}}\right)^{\frac{1}{1-\alpha}}\right)\right]}{\alpha A_{D} \frac{J_{2}}{J_{1}}-1}>0 \\
& \Sigma_{1} \equiv \frac{A_{D}\left(\frac{G_{1}}{F_{1}}\right)^{\frac{\alpha}{1-\alpha}}\left[(1-\alpha)\left(\frac{\gamma_{F}}{1+\beta_{F}}\left(\frac{A_{F}}{A_{D}}\right)^{\frac{1}{1-\alpha}}-\frac{\gamma_{D}}{1+\beta_{D}}\right)+\frac{\gamma_{D}}{1+\beta_{D}} \frac{\theta}{\phi}\left(1+\left(\frac{A_{F}}{A_{D}}\right)^{\frac{1}{1-\alpha}}\right)\right]}{\alpha A_{D} \frac{F_{1}}{G_{1}}-1}>0
\end{aligned}
$$

\footnotetext{
${ }^{8}$ Note that Assumption 5 implies $\max \left\{\left(\frac{A_{D}}{A_{F}}\right)^{\frac{1}{1-\alpha}} ; \frac{b_{D}}{b_{F}}\right\}=\left(\frac{A_{D}}{A_{F}}\right)^{\frac{1}{1-\alpha}}$. Thus, when Assumption 5 holds, Assumption 4 simplifies to $\frac{\gamma_{F}}{1+\beta_{F}}>\left(\frac{A_{D}}{A_{F}}\right)^{\frac{1}{1-\alpha}} \frac{\gamma_{D}}{1+\beta_{D}}$.

${ }^{9}$ In such a case, Propositions 2 and 3 will still apply, even if Assumption 2 does no more hold.
} 
Hence, there are only two steady states with $a_{D}>0$ and $a_{F}=0$ if $\Sigma>\max \left\{\Sigma_{0}, \Sigma_{1}\right\}$. In such a case, $k_{1}$ is higher than $k_{a}$ (see Figure 2). Starting from this situation, consider some debt transfers, which is to reduce $b_{F}$ and increase $b_{D}$ keeping $b_{D}+b_{F}$ identical. It implies a reduction of $\Sigma$. As shown in Appendix 7.5, this lowers $k_{1}$. When $b_{D} / b_{F}$ increases and tends to its upper bound $\left(b_{D} / b_{F}\right)^{+}, k_{1}$ decreases towards $k_{0}$. This means that there exists a value $\Sigma^{*}$ such that $k_{1}$ is lower than $k_{a}$ for $\Sigma<\Sigma^{*}$. It is clear that for $\Sigma<\Sigma^{*}$ and $\Sigma$ sufficiently close to $\Sigma^{*}$, one steady state $k_{l}\left(<k_{1}\right)$ with $a_{D}>0$ and $a_{F}=0$ coexists with one steady state $k_{h}^{s}\left(>k_{1}\right)$ with $a_{D}>0$ and $a_{F}>0$ (see Figure 3). Of course, we have $\Sigma^{*}<\min \left\{\Sigma_{0}, \Sigma_{1}\right\}$. Indeed, if $\Sigma>\Sigma_{0}, k_{h}$ is an admissible steady state, whereas if $\Sigma>\Sigma_{1}, k_{h}^{s}$ cannot be an admissible steady state.

We deduce the following proposition ${ }^{10}$ :

Proposition 6 Under Assumptions 1 and 3-5, $b_{D}$ and $b_{F}$ not too high, inequalities (34) and (44), there exists $\Sigma^{*} \in\left(0, \min \left\{\Sigma_{0}, \Sigma_{1}\right\}\right)$, such that:

1. If $\Sigma>\max \left\{\Sigma_{0}, \Sigma_{1}\right\}$, there exist two steady states with $a_{D}>0$ and $a_{F}=0, k_{l}$ and $k_{h}$;

2. If $\Sigma<\Sigma^{*}$ and $\Sigma$ sufficiently close to $\Sigma^{*}$, there exists one steady state $k_{l}$ with $a_{D}>0$ and $a_{F}=0$ and one steady state $k_{h}^{s}$ with $a_{D}>0$ and $a_{F}>0$.

Therefore, an increase of $b_{D}$ associated to a decrease of $b_{F}$ of the same amount may allow to move from a configuration where the two steady states are characterized by $a_{D}>0$ and $a_{F}=0$ to a configuration where the steady state with the lowest level of capital is characterized by $a_{D}>0$ and $a_{F}=0$ and the steady state with the highest level of capital by $a_{D}>0$ and $a_{F}>0$.

This proposition shows that following a decrease of debt in country $\mathrm{F}$ exactly compensated by an increase of debt in country $\mathrm{D}$, the long-run stable steady state moves from a configuration where environmental abatement is constrained in country $\mathrm{F}$ to a configuration where it is no more. The stability properties of the steady states presented in Proposition 6 are deduced from the analysis of Sections 5.1 and 5.2 and are illustrated in Figures 2 and 3.

\footnotetext{
${ }^{10}$ We are not interested in situations where environmental abatement of country $\mathrm{F}$ at the lowest steady state becomes positive, because we think that it is more relevant to analyse the policy implications on the stable steady state, which is characterized by the highest level of capital.
} 


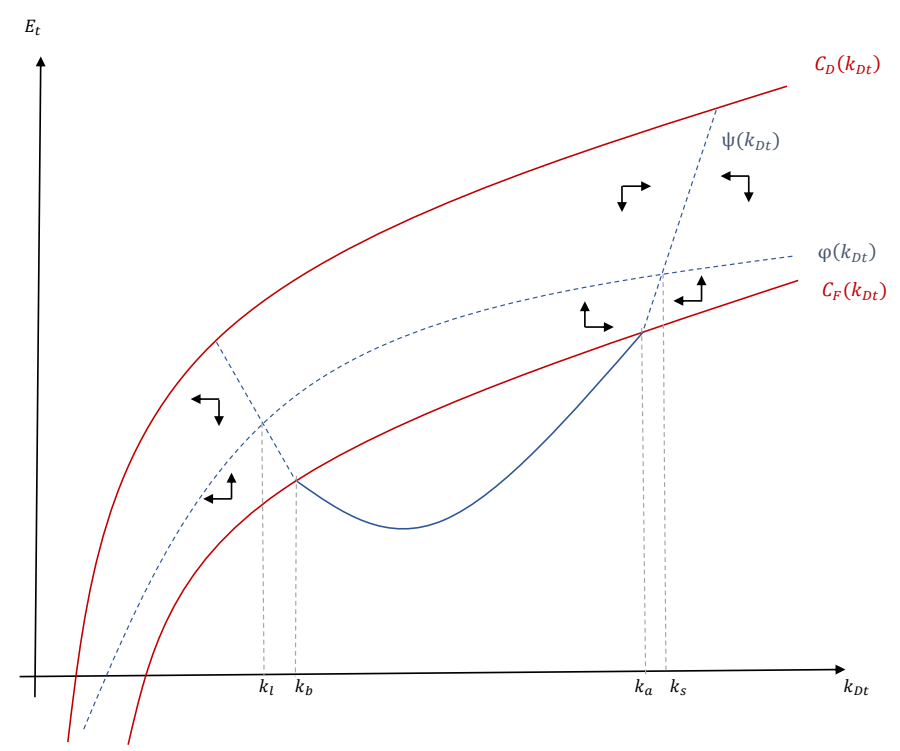

Figure 2 - Global dynamics for $\Sigma>\max \left\{\Sigma_{0}, \Sigma_{1}\right\}$

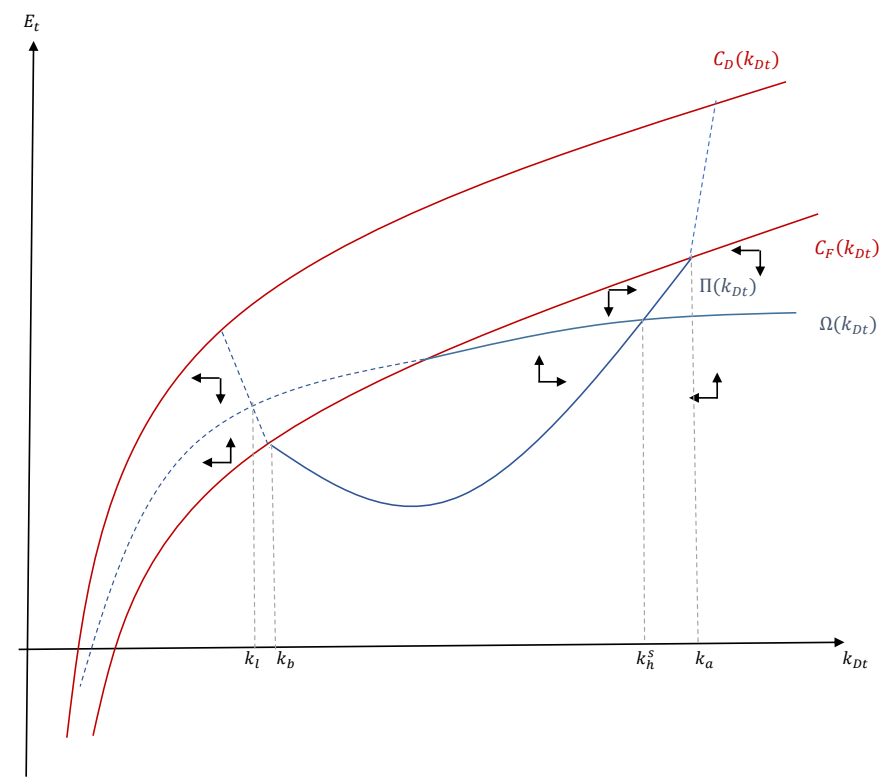

Figure 3 - Global dynamics for $\Sigma<\Sigma^{*}$

Proposition 6 requires a set of assumptions. They are compatible with each other. Indeed, Assumptions 1 and 5 imply that $A_{D} / A_{F}>\max \left\{\left(b_{D} / b_{F}\right)^{1-\alpha} ; 1\right\}$, which is satisfied for an appropriate set of the productivity parameters. Assumption 5 also requires the inequality $b_{D} / b_{F}<\left(b_{D} / b_{F}\right)^{+}$ which involves appropriate debt levels. Taking into account these restrictions, Assumption 4 which simplifies to $\frac{\gamma_{F}}{1+\beta_{F}}>\left(\frac{A_{D}}{A_{F}}\right)^{\frac{1}{1-\alpha}} \frac{\gamma_{D}}{1+\beta_{D}}$ is fulfilled for an appropriate set of the preference pa- 
rameters $\gamma_{F}$ and $\gamma_{D}$. Assumption 3 means a sufficiently low value of $\theta$. In this case, inequalities (34) and (44) are satisfied for $\beta_{i}$ low and $\alpha$ high enough, which are standard conditions to have under-accumulation.

Considering that all these assumptions are satisfied, Proposition 6 shows that a high enough debt transfer allows country $\mathrm{F}$ to engage into environmental mitigation. This occurs if either $\beta_{D}$ is higher or lower than $\beta_{F}$. Indeed, as we have already seen, the debt transfer means a lower fiscal pressure in country F. Therefore, if the debt transfer is significant, the after-tax income in country $\mathrm{F}$ is sufficiently high to finance also abatement. The marginal cost of engaging in abatement becomes equal to its marginal benefit (see the first order conditions (9)-(10) and (11)-(12)).

What is interesting is that we can further deduce some implications of the effect of such a policy on the levels of capital, environmental quality and welfare at the stable steady state. Using also Proposition 2, ${ }^{11}$ we see that when $\beta_{D}>\beta_{F}$, such a policy reduces the levels of capital and environmental quality at the steady state $k_{h}$ with $a_{D}>0$ and $a_{F}=0$. When the transfer of debt becomes high enough, the stable steady state is characterized by positive abatement in both countries and is no more affected by the debt transfer between countries that we consider (Proposition 5). In contrast, when $\beta_{D}<\beta_{F}$, the levels of capital and environmental quality at the steady state $k_{h}$ with $a_{D}>0$ and $a_{F}=0$ increase. Again, when the debt transfer is sufficiently high, the stable steady state enters the regime where both countries are engaged in environmental mitigation and becomes independent of the debt transfer considered. Using Proposition 3 and the property that the welfare can be expressed as a function of capital and environmental quality, we can deduce the effect of the debt transfer on capital, environmental quality and the welfare of each country.

Corollary 1 Under Assumptions 1 and 3-5, $b_{D}$ and $b_{F}$ not too high, $\alpha /(1-\alpha)>\max \left\{\frac{\beta_{D}}{1+\beta_{D}} ; \frac{\beta_{F}}{1+\beta_{F}}\right\}$, inequalities (34) and (44), a transfer of debt such that the economy moves from a stable steady state with no foreign contribution to environmental protection $\left(a_{F}=0\right)$ to a stable steady state with foreign contribution $\left(a_{F}>0\right)$, has the following implications:

- For $\beta_{D}>\beta_{F}$, capital, environmental quality and the welfare in the domestic country decreases while the impact is ambiguous for the welfare in the foreign one as long as $a_{F}=0$. When $a_{F}$ becomes strictly positive, all these variables become invariant to the policy.

- For $\beta_{D}<\beta_{F}$ and under condition (35), capital, environmental quality and the welfare in the foreign country increases while the impact is ambiguous for the welfare in the domestic country as long as $a_{F}=0$. When $a_{F}$ becomes strictly positive, all these variables become invariant to the policy.

Such a policy of transferring debt from country F to country D is relevant in terms of the level of capital, and also environmental quality, when country $\mathrm{D}$ is the most impatient one ( $\beta_{D}$ lower

\footnotetext{
${ }^{11}$ As we have already explained, Propositions 2 and 3 also hold when Assumption 2 is not satisfied.
} 
than $\left.\beta_{F}\right)$. The debt transfer from one country to the other one implies a reallocation of income net of taxes from country D to country F, since taxes increases in the first country, whereas it decreases in the other one. Taking into account the equilibrium on the international asset market (14) and (15), we know that capitals in both countries move in the same direction because the returns are equal. This means that capital will increase if global saving raises. This is possible if the redistribution of net income between countries is in favor of the population that saves more. Such a debt transfer also allows to raise welfare in country F, whereas the effect on the welfare of country D is not clear-cut. In addition, debt relief for poor countries can be used as a policy lever by rich countries to help them to engage in environmental protection. Nonetheless, we reveal that this instrument is useless once the unconstrained regime has been achieved. Therefore, the effect of public transfer is maximum when the economy switches from the regime with $a_{F}=0$ to the regime with $a_{F}>0$.

When country $\mathrm{D}$ is the most patient one $\left(\beta_{D}\right.$ higher than $\left.\beta_{F}\right)$, we have some opposite conclusions and economic mechanisms on capital and environmental quality. In addition, the negative effect of debt transfer is the highest on capital, environmental quality and the welfare of country $\mathrm{D}$ when one moves from the regime with $a_{F}=0$ to the regime with $a_{F}>0$. The impact on the welfare of country $\mathrm{F}$ is however unclear.

We could observe that while the effect of the debt transfer on the welfare of foreign country may be positive, it is never the case for the welfare of domestic country, without introducing some adding restrictions on the parameters. This asks the question of the implementability of the debt transfer for country D.

\section{Short remarks on perfect mobility of assets and redistribution of income}

Our setting with perfect capital mobility is a good approximation of what happens in countries with highly developed financial markets and few capital controls. To have a more general view, assuming imperfect capital mobility is a relevant option. When a debt transfer is implemented in such a case, capital accumulation is in part crowded out in the donor country. Assuming that the overall debt level is unchanged, this negative effect is offset if capital mobility is free, i.e if the donor shares a common asset market with the beneficiary. As long as capital is not perfectly mobile between countries, the donor would suffer from a crowding-out effect, in addition to a negative net income effect due to a higher level of taxes. Reversely, the program would favor the capital stock in the recipient country. The implementation of a debt transfer in a context of imperfect capital mobility would affect severely the capital stock and hence mitigation efforts in the rich country, while reverse results are observed in the poor country. Assuming that the poor country is initially less engaged in environmental action, this policy would not favor the global environmental quality. This suggests that perfect mobility of assets seems to be the most favorable configuration to implement a debt relief policy.

In this case of perfect mobility, a debt transfer implies a redistribution of income net of tax from the rich to the poor country. Indeed, recall that taxes paid by each country are given by 
$\tau_{i}=\left(\alpha A_{i} k_{i}^{\alpha-1}-1\right) b_{i}$, i.e. linearly depend on $b_{i}$. Therefore, any increase of $b_{D}$ exactly compensated by a decrease of $b_{F}$ means a redistribution of net income from country $\mathrm{D}$ to country $\mathrm{F}$. There is

however an adding effect that goes through the interest factor $\alpha A_{i} k_{i}^{\alpha-1}$, which (in)decreases if and only if capital (de)increases. As we have just seen above, when the mobility of assets becomes imperfect, the debt relief has also an effect through some crowding-out effect in some countries. The debt transfer does no more consist only in a redistribution of income as in the case of perfect mobility of asset. It is a way to direct financial help in favor of capital accumulation in the recipient country. Therefore, debt transfer can be seen as more general than just a redistribution of income through taxes.

\section{Concluding remarks}

Starting from the difficulties to implement effective environmental policies to fight pollutant emissions, the use of macroeconomic policy instruments. In an international context, we question the effect of debt transfer in favor of poor countries, the overall debt level remaining unchanged. Despite the fact that debt reliefs from rich to poor countries is actually an insignificant instrument used to promote climate change actions, we ask theoretically whether it should be more intensively considered.

We show that debt relief for poor countries, with low productivity, makes it possible to engage these countries in the process of pollution abatement. The efficiency of this policy strongly depends on the preferences of households in each country. Not only the sensitivity to environmental quality plays a key role, but also the time preference, that is a determinant of the saving rate. We highlight that, if the poor country is sufficiently patient, richer countries should help poorer countries to better fight pollutant emissions, even if indebted. This configuration gives interest to a debt relief in favor of poor countries. This conclusion does not applied if agents in the poor country are impatient. In that case, we reveal that there are some limits to implement debt transfer to achieve global environmental objectives. Debt transfer should be accompanied by other policy programs, aiming at modifying behaviors for instance. Otherwise, it is damaging for the environment and reduces the stock of capital, even if it can favor the participation of the poor-impatient country to mitigate climate change. Thus, our results provide intuitions about the difficulties of aid transfer programs to improve the donor and the recipient well-being, and the conditions to make them effective.

\section{Appendix}

\subsection{Phase diagram when $\gamma_{F}$ is arbitrarily small and close to 0}

We easily see from $(30)$, that $\varphi\left(k_{D t}\right)$ is strictly increasing $\left(\varphi\left(k_{D t}\right)^{\prime}>0\right)$ and concave $\left(\varphi\left(k_{D t}\right)^{\prime \prime}<\right.$ $0)$, with $\lim _{k_{D t} \rightarrow 0} \varphi\left(k_{D t}\right)=-\infty$ and $\lim _{k_{D t} \rightarrow+\infty} \varphi\left(k_{D t}\right)=+\infty$.

Using equation (31), we have $\lim _{k_{D t} \rightarrow 0} \psi\left(k_{D t}\right)=+\infty$ and $\lim _{k_{D t} \rightarrow+\infty} \psi\left(k_{D t}\right)=+\infty$, with 
$\lim _{k_{D t} \rightarrow+\infty} \psi\left(k_{D t}\right) / \varphi\left(k_{D t}\right)=+\infty$. We can also show that $\psi^{\prime \prime}\left(k_{D t}\right)>0$. Since $\lim _{k_{D t} \rightarrow 0} \psi^{\prime}\left(k_{D t}\right)=$ $-\infty$ and $\lim _{k_{D t} \rightarrow+\infty} \psi^{\prime}\left(k_{D t}\right)>0, \psi\left(k_{D t}\right)$ is a convex function, decreasing for low values of $k_{D t}$ and increasing for high values of $k_{D t}$.

By direct inspection of (30) and (32), we easily see that $C_{D}\left(k_{D t}\right)$ is increasing and concave, with $\lim _{k_{D t} \rightarrow 0} C_{D}\left(k_{D t}\right)=-\infty, \lim _{k_{D t} \rightarrow+\infty} C_{D}\left(k_{D t}\right)=+\infty$ and $C_{D}\left(k_{D t}\right)>\varphi\left(k_{D t}\right)$ for all $k_{D t}>0$.

By direct inspection of equation (33), under Assumptions 1-3, the two terms into brackets are positive. It implies that $C_{F}\left(k_{D t}\right)$ is decreasing and convex, with $\lim _{k_{D t} \rightarrow 0} C_{F}\left(k_{D t}\right)=+\infty$ and $\lim _{k_{D t} \rightarrow+\infty} C_{F}\left(k_{D t}\right)=-\infty$

Now, we examine the conditions such that $\varphi\left(k_{D t}\right)>C_{F}\left(k_{D t}\right)$ :

Lemma 1 Under Assumptions 1-3, there exists $\bar{k}>0$ such that $\varphi\left(k_{D t}\right)>\max \left\{0 ; C_{F}\left(k_{D t}\right)\right\}$ for all $k_{D t}>\bar{k}$.

Proof. Using (30) and (33), $\varphi\left(k_{D t}\right) \geqslant C_{F}\left(k_{D t}\right)$ is equivalent to $F\left(k_{D t}\right) \leqslant \widetilde{F}$, with:

$$
\begin{aligned}
F\left(k_{D t}\right) & \equiv \alpha k_{D t}^{-1}-\frac{1}{A_{D}} k_{D t}^{-\alpha} \\
\widetilde{F} & \equiv \frac{\left[\phi(1-\alpha)-\theta\left(1+\left(\frac{A_{F}}{A_{D}}\right)^{\frac{1}{1-\alpha}}\right)\right] \frac{\gamma_{D}}{1+\beta_{D}}-\phi(1-\alpha)\left(\frac{A_{F}}{A_{D}}\right)^{\frac{1}{1-\alpha}} \frac{\gamma_{F}}{1+\beta_{F}}}{\phi\left(\frac{b_{D} \gamma_{D}}{1+\beta_{D}}-\frac{b_{F} \gamma_{F}}{1+\beta_{F}}\right)}>0
\end{aligned}
$$

We can show that $F\left(k_{D t}\right)$ decreases from $+\infty$ to $\underline{F} \equiv(\alpha-1) A_{D}^{-\frac{1}{1-\alpha}}(<0)$ when $k_{D t}$ increases from 0 to $\widehat{k} \equiv A_{D}^{\frac{1}{1-\alpha}}$ and increases to 0 when $k_{D t}$ increases from $\widehat{k}$ to $+\infty$. Using these properties, there is a unique $k_{1}>0$ such that $F\left(k_{D t}\right) \leqslant \widetilde{F}$ for all $k_{t} \geqslant k_{1}$.

Moreover, $\varphi\left(k_{D t}\right)>0$ is equivalent to $F\left(k_{D t}\right)<F_{0}$, with:

$$
F_{0} \equiv \frac{\phi(1-\alpha)-\theta\left(1+\left(\frac{A_{F}}{A_{D}}\right)^{\frac{1}{1-\alpha}}\right)}{\phi b_{D}}
$$

there is a unique $k_{0}>0$ such that $F\left(k_{D t}\right)<F_{0}$ for all $k_{t}>k_{0}$. We deduce the lemma by noting $\underline{k}=\max \left\{k_{1} ; k_{0}\right\}$.

For all $k_{D t}>k_{1}$, we have $C_{D}\left(k_{D t}\right)>\varphi\left(k_{D t}\right)>C_{F}\left(k_{D t}\right)$. To construct a phase digram and be able to have a picture of global dynamics, we also need to analyse whether $\psi\left(k_{D t}\right) \geqslant C_{F}\left(k_{D t}\right)$. Using (31) and (33), this inequality is equivalent to $\Gamma\left(k_{D t}\right) \geqslant 0$, with:

$$
\begin{aligned}
\Gamma\left(k_{D t}\right) \equiv & k_{D t}\left[1+\left(\frac{A_{F}}{A_{D}}\right)^{\frac{1}{1-\alpha}}\right]-k_{D t}^{\alpha}(1-\alpha) A_{D}\left(\frac{A_{F}}{A_{D}}\right)^{\frac{1}{1-\alpha}}\left(\frac{\beta_{F}}{1+\beta_{F}}+\frac{\beta_{D}}{1+\beta_{F}} \frac{\gamma_{F}}{\gamma_{D}}\right) \\
& -\alpha k_{D t}^{\alpha-1}\left[A_{D}\left(\frac{\beta_{D} b_{D}}{1+\beta_{D}+\gamma_{D}}-\frac{\beta_{D} \gamma_{F} b_{F}}{\left(1+\beta_{F}\right) \gamma_{D}}\right)-A_{F}\left(\frac{\beta_{F} b_{F}}{1+\beta_{F}}+\frac{\beta_{D} b_{D}}{1+\beta_{D}+\gamma_{D}}\right)\right] \\
& +b_{D}+\frac{b_{F}}{1+\beta_{F}}\left[1-\frac{\gamma_{F} \beta_{D}}{\gamma_{D}}\right]
\end{aligned}
$$


We deduce that $\lim _{k_{D t} \rightarrow+\infty} \Gamma\left(k_{D t}\right)=+\infty$, which means that there is a value of $k$ above which $\psi\left(k_{D t}\right) \geqslant C_{F}\left(k_{D t}\right)$.

\subsection{Proof of Proposition 1}

A steady state is a solution $\left(E_{t}, k_{D t}\right)=\left(E_{t+1}, k_{D t+1}\right)=\left(E, k_{D}\right)$ satisfying equations $(27)$ and (28):

$$
\begin{aligned}
& \frac{\beta_{D}}{\gamma_{D} \phi} E=k_{D}\left[1+\left(\frac{A_{F}}{A_{D}}\right)^{\frac{1}{1-\alpha}}\right] \\
& +b_{D}+\frac{b_{F}}{1+\beta_{F}}-\frac{\beta_{F}}{1+\beta_{F}}\left[(1-\alpha) A_{F} k_{D}^{\alpha}\left(\frac{A_{F}}{A_{D}}\right)^{\frac{\alpha}{1-\alpha}}-b_{F} \alpha A_{D} k_{D}^{\alpha-1}\right] \\
& \frac{1+\beta_{D}}{\gamma_{D}} E=-\phi b_{D}\left[\alpha A_{D} k_{D}^{\alpha-1}-1\right]+A_{D} k_{D}^{\alpha}\left[\phi(1-\alpha)-\theta\left(1+\left(\frac{A_{F}}{A_{D}}\right)^{\frac{1}{1-\alpha}}\right)\right]
\end{aligned}
$$

Using these two equations and substituting $E$, a steady state solves $H_{1}\left(k_{D}\right)=H_{2}\left(k_{D}\right)$, where:

$$
\begin{aligned}
& H_{1}\left(k_{D}\right)=G_{1} k_{D}^{\alpha}-F_{1} k_{D} \\
& H_{2}\left(k_{D}\right)=G_{2} k_{D}^{\alpha-1}+F_{2}
\end{aligned}
$$

with:

$$
\begin{aligned}
F_{1} & =1+\left(\frac{A_{F}}{A_{D}}\right)^{\frac{1}{1-\alpha}}>0 \\
G_{1} & =A_{F} \frac{\beta_{F}}{1+\beta_{F}}(1-\alpha)\left(\frac{A_{F}}{A_{D}}\right)^{\frac{\alpha}{1-\alpha}}+A_{D} \frac{\beta_{D}}{1+\beta_{D}}\left[1-\alpha-\frac{\theta}{\phi}\left(1+\left(\frac{A_{F}}{A_{D}}\right)^{\frac{1}{1-\alpha}}\right)\right]>0 \\
F_{2} & =\frac{b_{D}}{1+\beta_{D}}+\frac{b_{F}}{1+\beta_{F}}>0 \\
G_{2} & =\alpha A_{D}\left(\frac{b_{D} \beta_{D}}{1+\beta_{D}}+\frac{b_{F} \beta_{F}}{1+\beta_{F}}\right)>0
\end{aligned}
$$

See also Figure 4 which illustrates this steady state analysis with $X_{1}=H_{1}$ and $X_{2}=H_{2}$.

When $b_{D}=b_{F}=0$, we have $F_{2}=G_{2}=0$. Steady states are solutions solving $H_{1}\left(k_{D}\right)=0$. There are two solutions, $k_{D}=0$ and $k_{D}=\left(G_{1} / F_{1}\right)^{\frac{1}{1-\alpha}} \equiv \widehat{k} .{ }^{12}$ We note that $H_{1}\left(k_{D}\right)$ is an inverse U-shaped strictly concave function which attains its maximum value for $k_{D}=\left(\alpha G_{1} / F_{1}\right)^{\frac{1}{1-\alpha}} \equiv \bar{k}$. This maximum value is equal to:

$$
H_{1}(\bar{k})=\alpha^{\frac{\alpha}{1-\alpha}} G_{1}^{\frac{1}{1-\alpha}} F_{1}^{-\frac{\alpha}{1-\alpha}}(1-\alpha) \equiv \bar{H}_{1}
$$

By direct inspection of (59), we also see that, for a strictly positive $b_{D}$ and/or $b_{F}, H_{2}\left(k_{D}\right)$ is strictly decreasing and convex, with $\lim _{k_{D} \rightarrow 0} H_{2}\left(k_{D}\right)=+\infty$ and $\lim _{k_{D} \rightarrow+\infty} H_{2}\left(k_{D}\right)=F_{2}$. In

\footnotetext{
${ }^{12}$ We recover the result presented in Muller-Furstenberger and Schumacher (2017), i.e without any debt there is one unique non-trivial steady state.
} 
addition, we have $H_{2}(\bar{k})=F_{2}+G_{2} F_{1} /\left(\alpha G_{1}\right)$. Then, $H_{2}(\bar{k}) \leqslant H_{1}(\bar{k})$ if:

$$
\alpha F_{2} G_{1}+G_{2} F_{1} \leqslant(1-\alpha) \alpha^{\frac{1}{1-\alpha}} G_{1}^{\frac{2-\alpha}{1-\alpha}} F_{1}^{-\frac{\alpha}{1-\alpha}}
$$

Using (62) and (63), we easily deduce that this last inequality is satisfied if $b_{D}$ and $b_{F}$ are low enough. In this case, there are two stationary solutions to the equation $H_{1}\left(k_{D}\right)=H_{2}\left(k_{D}\right)$. Since a steady state satisfies (57), inequality (25) is fulfilled. We also note that since (56) and (57) are independent of the parameter $\gamma_{F}$, a steady state $\left(k_{D}, E\right)$ does not depend on $\gamma_{F}$. Therefore, inequality (26) evaluated at a steady state is satisfied for $\gamma_{F}$ small enough. More precisely, for a small $\gamma_{F}$, each steady state satisfies the condition to be in an asymmetric regime, i.e $\varphi\left(k_{D}\right)>C_{F}\left(k_{D}\right)$.

From (65), if the following sufficient condition holds:

$$
F_{2}>(1-\alpha) \alpha^{\frac{\alpha}{1-\alpha}} G_{1}^{\frac{1}{1-\alpha}} F_{1}^{-\frac{\alpha}{1-\alpha}}
$$

we have $H_{2}\left(k_{D}\right)>H_{1}\left(k_{D}\right)$ for all $k_{D}>0$ and there is no steady state. This last inequality is satisfied if $b_{D}$ and/or $b_{F}$ are sufficiently high.

We further note that since both steady states are lower than $\widehat{k}=\left(G_{1} / F_{1}\right)^{\frac{1}{1-\alpha}}$, they are characterized by under-accumulation if $\widehat{k}<\left(\alpha A_{D}\right)^{\frac{1}{1-\alpha}}$. Using (60) and (61), it is equivalent to:

$$
\frac{\alpha}{1-\alpha}>\frac{\frac{\beta_{D}}{1+\beta_{D}}+\frac{\beta_{F}}{1+\beta_{F}}\left(\frac{A_{F}}{A_{D}}\right)^{\frac{1}{1-\alpha}}}{1+\left(\frac{A_{F}}{A_{D}}\right)^{\frac{1}{1-\alpha}}}
$$

\subsection{Proof of Proposition 2}

We examine the impact of debt variation on the stationary capital stocks and environmental quality index. Using (58)-(63), we obtain:

$$
\frac{d k_{D}}{d b_{i}}=\frac{\frac{\beta_{i}}{1+\beta_{i}} \alpha A_{D} k_{D}^{\alpha-1}+\frac{1}{1+\beta_{i}}}{H_{1}^{\prime}\left(k_{D}\right)-H_{2}^{\prime}\left(k_{D}\right)}, \text { for } i=\{D, F\}
$$

We consider the following variation: $d b_{D}=-d b_{F}=d b$. Using (67), we get:

$$
\frac{d k_{D}}{d b}=\frac{\left(\alpha A_{D} k_{D}^{\alpha-1}-1\right)\left(\frac{\beta_{D}}{1+\beta_{D}}-\frac{\beta_{F}}{1+\beta_{F}}\right)}{H_{1}^{\prime}\left(k_{D}\right)-H_{2}^{\prime}\left(k_{D}\right)}
$$

We deduce the effect of debt transfer on capital taking into account that $H_{1}^{\prime}\left(k_{D}\right)<H_{2}^{\prime}\left(k_{D}\right)$ when $k_{D}=k_{h}$.

Then, we analyze how the environmental quality that prevails at the high steady state, i.e 
$E_{h}$, evolves with a debt transfer. Using (57) we have:

$$
\begin{aligned}
\frac{1+\beta_{D}}{\gamma_{D}} \frac{d E_{h}}{d b}= & -\phi\left(\alpha A_{D} k_{h}^{\alpha-1}-1\right)+\phi b_{D} A_{D} \alpha(1-\alpha) k_{h}^{\alpha-2} \frac{d k_{h}}{d b} \\
& +\alpha A_{D} k_{h}^{\alpha-1} \frac{d k_{h}}{d b}\left[\phi(1-\alpha)-\theta\left(1+\left(\frac{A_{F}}{A_{D}}\right)^{\frac{1}{1-\alpha}}\right)\right]
\end{aligned}
$$

When $\beta_{D}>\beta_{F}$, we deduce that $d E_{h} / d b<0$. We rewrite the previous expression to examine the case $\beta_{F}>\beta_{D}$ :

$\frac{1+\beta_{D}}{\gamma_{D}} \frac{d E_{h}}{d b}=\phi+\phi A_{D} \alpha k_{h}^{\alpha-1}\left[(1-\alpha) \epsilon_{k_{h} / b}-1\right]+\alpha A_{D} k_{h}^{\alpha-1} \frac{d k_{h}}{d b}\left[\phi(1-\alpha)-\theta\left(1+\left(\frac{A_{F}}{A_{D}}\right)^{\frac{1}{1-\alpha}}\right)\right]$

with $\epsilon_{k_{h} / b} \equiv \frac{d k_{h}}{d b} \frac{b_{D}}{k_{h}}$. Under Assumptions 1-3, $\epsilon_{k_{h} / b}$ is decreasing with $k_{h}$. By inspection of equation (68), this is easily shown by observing that $H_{2}^{\prime \prime}\left(k_{D}\right)>0, H_{1}^{\prime \prime}\left(k_{D}\right)<0$ and the steady state level of capital is characterized by under-accumulation.

We also have $\frac{d k_{h}}{d b}>0$ if inequality (34) is satisfied and $\beta_{F}>\beta_{D}$. As a result, the condition $\epsilon_{k_{h} / b}>1 /(1-\alpha)$ guarantees $\frac{d E_{h}}{d b}>0$. As the elasticity $\epsilon_{k_{h} / b}$ is a decreasing function of $k_{h}$ and that $k_{h}<\hat{k}$, a sufficient condition is to have

$$
\epsilon_{\hat{k} / b} \equiv \frac{d \hat{k}}{d b} \frac{b_{D}}{\hat{k}}>1 /(1-\alpha)
$$

Using (58)-(63) and (67), this condition corresponds to

$$
\frac{\left(1+\beta_{D}\right)\left(1+\beta_{F}\right)}{b_{D}\left(\beta_{F}-\beta_{D}\right)}<\frac{\alpha A_{D} F_{1}-G_{1}}{G_{1}^{\frac{2-\alpha}{1-\alpha}} F_{1}^{\frac{-\alpha}{1-\alpha}}-G_{2} F_{1}} \equiv \mathcal{X}
$$

and Proposition 2 follows.

\subsection{Proof of Proposition 3}

We then examine the effect of a debt transfer on the agent's welfare in both economies. Using agent's consumption choices, its indirect utility function along the high steady state is given by:

$$
V_{i}=\left(1+\beta_{i}\right) \ln \left(c_{i}\right)+\beta_{i} \ln \left(R_{i}\right)+\left(\delta_{i}+\gamma_{i}\right) \ln \left(E_{h}\right)+\beta_{i} \ln \beta_{i}
$$

We decompose the welfare into a consumption $\left(V_{C i}\right)$ and an environmental $\left(V_{E i}\right)$ components.

$$
V_{i}=\underbrace{\left(1+\beta_{i}\right) \ln \left(c_{i}\right)+\beta_{i} \ln \left(R_{i}\right)}_{V_{C i}}+\underbrace{\left(\delta_{i}+\gamma_{i}\right) \ln \left(E_{h}\right)}_{V_{E i}}+\beta_{i} \ln \beta_{i}
$$

The environmental part of the welfare evolves as the environment. We have $\operatorname{Sign} \frac{d V_{E i}}{d b}=\operatorname{Sign} \frac{d E_{h}}{d b}$. 
Then, we examine how the consumption part of the welfare changes with a debt transfer.

$$
\operatorname{Sign} \frac{d V_{C i}}{d b}=\operatorname{Sign}\left\{\left(1+\beta_{i}\right) \frac{d c_{i}}{d b} R_{i}+\beta_{i} \frac{d R_{i}}{d b} c_{i}\right\}
$$

Given (14), we have

$$
\frac{d R_{F}}{d b}=\frac{d R_{D}}{d b}=A_{D} \alpha(\alpha-1) k_{h}^{\alpha-2} \frac{d k_{h}}{d b}
$$

Using (9), (11) and (57) we have:

$$
\begin{aligned}
& c_{D}=\frac{E}{\gamma_{D} \phi}=\frac{1}{1+\beta_{D}}\left[A_{D} k_{D}^{\alpha}\left(1-\alpha-\frac{\theta}{\phi}\left(1+\left(\frac{A_{F}}{A_{D}}\right)^{\frac{1}{1-\alpha}}\right)\right)-b_{D}\left(\alpha A_{D} k_{D}^{\alpha-1}-1\right)\right] \\
& c_{F}=\frac{1}{1+\beta_{F}}\left(w_{F}-\tau_{F}\right)=\frac{1}{1+\beta_{F}}\left[(1-\alpha) A_{D} k_{D}^{\alpha}\left(\frac{A_{F}}{A_{D}}\right)^{\frac{1}{1-\alpha}}-b_{F}\left(\alpha A_{D} k_{D}^{\alpha-1}-1\right)\right]
\end{aligned}
$$

Differentiating these equations, we get:

$$
\begin{gathered}
\left(1+\beta_{D}\right) \frac{d c_{D}}{d b}=\alpha A_{D} k_{h}^{\alpha-1}\left[(1-\alpha)-\frac{\theta}{\phi}\left(1+\left(\frac{A_{F}}{A_{D}}\right)^{\frac{1}{1-\alpha}}\right)\right] \frac{d k_{h}}{d b}-\left(R_{D}-1\right)+b_{D} \alpha(1-\alpha) A_{D} k_{D}^{\alpha-2} \frac{d k_{h}}{d b} \\
\left(1+\beta_{F}\right) \frac{d c_{F}}{d b}=\alpha A_{D} k_{h}^{\alpha-1}(1-\alpha) \frac{d k_{h}}{d b}\left(\frac{A_{F}}{A_{D}}\right)^{\frac{1}{1-\alpha}}+\left(R_{F}-1\right)+b_{F} \alpha(1-\alpha) A_{D} k_{h}^{\alpha-2} \frac{d k_{h}}{d b}
\end{gathered}
$$

Finally, the sign of $d V_{C D} / d b$ is given by the sign of:

$$
\begin{aligned}
& \underbrace{\left(1-\frac{(1-\alpha) \beta_{D}}{\alpha\left(1+\beta_{D}\right)}\right)\left[(1-\alpha)-\frac{\theta}{\phi}\left(1+\left(\frac{A_{F}}{A_{D}}\right)^{\frac{1}{1-\alpha}}\right)\right] \frac{d k_{h}}{d b} R_{D}^{2}}_{\text {income effect }} \\
& +\underbrace{\frac{b_{D} R_{D}(1-\alpha)}{k_{h}}\left(R_{D}+\frac{\left(R_{D}-1\right) \beta_{D}}{1+\beta_{D}}\right) \frac{d k_{h}}{d b}}_{\text {debt burden effect }}-\underbrace{\left(R_{D}-1\right) R_{D}}_{\text {direct debt effect }}
\end{aligned}
$$

and the sign of $d V_{C F} / d b$ by the sign of:

$$
\begin{aligned}
& \left(1-\frac{(1-\alpha) \beta_{F}}{\alpha\left(1+\beta_{F}\right)}\right) \frac{d k_{h}}{d b}\left(\frac{A_{F}}{A_{D}}\right)^{\frac{1}{1-\alpha}}(1-\alpha) R_{F}^{2} \\
& +\frac{b_{F} R_{F}(1-\alpha)}{k_{h}}\left(R_{F}+\frac{\left(R_{F}-1\right) \beta_{F}}{1+\beta_{F}}\right) \frac{d k_{h}}{d b}+\left(R_{F}-1\right) R_{F}
\end{aligned}
$$

By inspection of (70) and (71), the income effect in both countries is positive when $\alpha /(1-\alpha)>$ $\max \left\{\frac{\beta_{D}}{1+\beta_{D}} ; \frac{\beta_{F}}{1+\beta_{F}}\right\}$. This condition ensures that the two countries under-accumulates capital. In this case, the condition (34) that guarantees that the capital at the international level is necessarily lower than the golden rule is always satisfied.

Proposition 3 follows from these last results. 


\subsection{Phase diagram when $\gamma_{F}$ is significant}

Lemma 2 Under Assumptions 1, 3 and 4, there exists $k_{1}>0$ such that $C_{F}\left(k_{D t}\right)<\varphi\left(k_{D t}\right)$ for all $k_{D t}<k_{1}$. This upper bound $k_{1}$ increases with $\frac{b_{F} \gamma_{F}}{1+\beta_{F}}-\frac{b_{D} \gamma_{D}}{1+\beta_{D}}$. In addition, there exists $k_{0}\left(<k_{1}\right)$ such that $\varphi\left(k_{D t}\right)>0$ for all $k_{D t}>k_{0}$ if:

$$
\frac{b_{D}}{b_{F}}<\frac{\phi(1-\alpha)-\theta\left(1+\left(\frac{A_{F}}{A_{D}}\right)^{\frac{1}{1-\alpha}}\right)}{\phi(1-\alpha)\left(\frac{A_{F}}{A_{D}}\right)^{\frac{1}{1-\alpha}}}
$$

Proof. Since $\frac{b_{F} \gamma_{F}}{1+\beta_{F}}>\frac{b_{D} \gamma_{D}}{1+\beta_{D}}, \varphi\left(k_{D t}\right)>C_{F}\left(k_{D t}\right)$ is equivalent to $F\left(k_{D t}\right)>\widetilde{F}$, where $F\left(k_{D t}\right)$ is given by (52) and $\widetilde{F}$ by (53). Under Assumption $4, \widetilde{F}>0$ which means that there exists a unique $k_{1}>0$ such that $F\left(k_{D t}\right)>\widetilde{F}$ for all $k_{D t}<k_{1}$. Using (52) and (53), we also deduce that $k_{1}$ increases with $\frac{b_{F} \gamma_{F}}{1+\beta_{F}}-\frac{b_{D} \gamma_{D}}{1+\beta_{D}}$.

Moreover, $\varphi\left(k_{D t}\right)>0$ is equivalent to $F\left(k_{D t}\right)<F_{0}$, with $F_{0}>0$ given by $(54) . F_{0}>\widetilde{F}$ is ensured by inequality (72). In this case, there exists $k_{0}$ lower than $k_{1}$ such that $F\left(k_{D t}\right)<F_{0}$ for all $k_{D t}>k_{0}$.

We still have that $\psi\left(k_{D t}\right) \geqslant C_{F}\left(k_{D t}\right)$ is equivalent to $\Gamma\left(k_{D t}\right) \geqslant 0$, where $\Gamma\left(k_{D t}\right)$ is given by $(55)$. However, under Assumption 4, we deduce that $\lim _{k_{D t} \rightarrow 0} \Gamma\left(k_{D t}\right)=+\infty, \lim _{k_{D t} \rightarrow+\infty} \Gamma\left(k_{D t}\right)=+\infty$ and $\Gamma\left(k_{D t}\right)$ is convex:

$$
\begin{aligned}
& \Gamma^{\prime \prime}\left(k_{D t}\right)=k_{D t}^{\alpha-2} \alpha(1-\alpha)^{2} A_{D}\left(\frac{A_{F}}{A_{D}}\right)^{\frac{1}{1-\alpha}}\left(\frac{\beta_{F}}{1+\beta_{F}}+\frac{\beta_{D}}{1+\beta_{F}} \frac{\gamma_{F}}{\gamma_{D}}\right) \\
& -\alpha(\alpha-1)(\alpha-2) k_{D t}^{\alpha-3}\left[A_{D}\left(\frac{\beta_{D} b_{D}}{1+\beta_{D}+\gamma_{D}}-\frac{\beta_{D} \gamma_{F} b_{F}}{\left(1+\beta_{F}\right) \gamma_{D}}\right)-A_{F}\left(\frac{\beta_{F} b_{F}}{1+\beta_{F}}+\frac{\beta_{D} b_{D}}{1+\beta_{D}+\gamma_{D}}\right)\right] \geqslant 0
\end{aligned}
$$

This means that $\psi\left(k_{D t}\right)$ is higher than $C_{F}\left(k_{D t}\right)$ at least for $k_{D t}$ low or high enough.

Under Assumption 3, we observe, using (42), that $\Omega\left(k_{D t}\right)$ is strictly increasing $\left(\Omega\left(k_{D t}\right)^{\prime}>0\right)$ and concave $\left(\Omega\left(k_{D t}\right)^{\prime \prime}<0\right)$, with $\lim _{k_{D t} \rightarrow 0} \Omega\left(k_{D t}\right)=-\infty$ and $\lim _{k_{D t} \rightarrow+\infty} \Omega\left(k_{D t}\right)=+\infty$.

By inspection of equation (43), we have $\lim _{k_{D t} \rightarrow 0} \Pi\left(k_{D t}\right)=+\infty$ and $\lim _{k_{D t} \rightarrow+\infty} \Pi\left(k_{D t}\right)=$ $+\infty$, with $\lim _{k_{D t} \rightarrow+\infty} \Pi\left(k_{D t}\right) / \Omega\left(k_{D t}\right)=+\infty$. We can also show that $\Pi^{\prime \prime}\left(k_{D t}\right)>0$. Since $\lim _{k_{D t} \rightarrow 0} \Pi^{\prime}\left(k_{D t}\right)=-\infty$ and $\lim _{k_{D t} \rightarrow+\infty} \Pi^{\prime}\left(k_{D t}\right)>0, \Pi\left(k_{D t}\right)$ is a convex function, decreasing for low values of $k_{D t}$ and increasing for high values of $k_{D t}$.

We can further study whether $C_{F}\left(k_{D t}\right) \geqslant \Omega\left(k_{D t}\right)$. After some computations, we can show that when $\frac{b_{F} \gamma_{F}}{1+\beta_{F}}>\frac{b_{D} \gamma_{D}}{1+\beta_{D}}$, this inequality is equivalent to $F\left(k_{D t}\right) \leqslant \widetilde{F}$. Using Lemma 2, we immediately deduce that this is satisfied for $k_{D t} \geqslant k_{1}$. This means of course that $\varphi\left(k_{1}\right)=\Omega\left(k_{1}\right)$. 


\subsection{Proof of Proposition 4}

A steady state is defined by $E=\Omega\left(k_{D}\right)$ and

$$
\frac{1}{\phi} E\left(\frac{\beta_{D}}{\gamma_{D}}+\frac{\beta_{F}}{\gamma_{F}}\right)=k_{D}\left[1+\left(\frac{A_{F}}{A_{D}}\right)^{\frac{1}{1-\alpha}}\right]+b_{D}+b_{F}
$$

with $E<\min \left\{C_{F}\left(k_{D}\right), C_{D}\left(k_{D}\right)\right\}$. Using these equations, a steady state is a solution $k_{D}$ to the equation $I\left(k_{D}\right)=J\left(k_{D}\right)$, with:

$$
\begin{aligned}
& I\left(k_{D}\right)=I_{1}+I_{2} k_{D}^{\alpha-1} \\
& J\left(k_{D}\right)=J_{1} k_{D}^{\alpha}-J_{2} k_{D}
\end{aligned}
$$

and

$$
\begin{aligned}
& I_{1}=\left(b_{D}+b_{F}\right) \frac{\gamma_{F}+\gamma_{D}}{\left(1+\beta_{D}\right) \gamma_{F}+\left(1+\beta_{F}\right) \gamma_{D}}>0 \\
& I_{2}=\left(b_{D}+b_{F}\right) \frac{\gamma_{F} \beta_{D}+\gamma_{D} \beta_{F}}{\left(1+\beta_{D}\right) \gamma_{F}+\left(1+\beta_{F}\right) \gamma_{D}} \alpha A_{D}>0 \\
& J_{1}=\frac{\left(\gamma_{F} \beta_{D}+\gamma_{D} \beta_{F}\right) A_{D}[\phi(1-\alpha)-\theta]\left[1+\left(\frac{A_{F}}{A_{D}}\right)^{\frac{1}{1-\alpha}}\right]}{\left(1+\beta_{D}\right) \gamma_{F}+\left(1+\beta_{F}\right) \gamma_{D}}>0 \\
& J_{2}=1+\left(\frac{A_{F}}{A_{D}}\right)^{\frac{1}{1-\alpha}} \equiv F_{1}>0
\end{aligned}
$$

The analysis for the existence and multiplicity of steady states is quite similar to the case with $a_{D t}>0$ and $a_{F t}=0$. Figure 4 illustrates the steady state analysis for the symmetric case, with $X_{1}=I$ and $X_{2}=J$. Indeed, $J\left(k_{D}\right)$ is an inverse U-shaped strictly concave function which attains its maximum value for $k_{D}=\left(\alpha J_{1} / J_{2}\right)^{\frac{1}{1-\alpha}} \equiv k_{J}$, with:

$$
J\left(k_{J}\right)=\alpha^{\frac{\alpha}{1-\alpha}} J_{1}^{\frac{1}{1-\alpha}} J_{2}^{-\frac{\alpha}{1-\alpha}}(1-\alpha)
$$

If $b_{D}+b_{F}=0$, we have $I_{1}=I_{2}=0$. Steady states are solutions solving $J\left(k_{D}\right)=0$. There are two solutions, $k_{D}=0$ and $k_{D}=\left(J_{1} / J_{2}\right)^{\frac{1}{1-\alpha}} \equiv \widehat{k}^{s}$.

If $b_{D}+b_{F}>0$, we see that $I\left(k_{D}\right)$ is strictly decreasing and convex, with $\lim _{k_{D} \rightarrow 0} I\left(k_{D}\right)=+\infty$ and $\lim _{k_{D} \rightarrow+\infty} I\left(k_{D}\right)=I_{1}$. We have $I\left(k_{J}\right) \leqslant J\left(k_{J}\right)$ iff:

$$
\alpha J_{1} I_{1}+J_{2} I_{2} \leqslant(1-\alpha) \alpha^{\frac{1}{1-\alpha}} J_{1}^{\frac{2-\alpha}{1-\alpha}} J_{2}^{-\frac{\alpha}{1-\alpha}}
$$

Using (76)-(79), we note that $J_{1}$ and $J_{2}$ do not depend on $b_{D}$ and $b_{F}$, while $I_{1}$ and $I_{2}$ both linearly increase with $b_{D}+b_{F}$. Therefore, inequality (81) is satisfied if $b_{D}+b_{F}$ is low enough. In this case, there are two stationary solutions to the equation $H_{1}\left(k_{D}\right)=H_{2}\left(k_{D}\right)$. The steady states are admissible if $E<\min \left\{C_{F}\left(k_{D}\right), C_{D}\left(k_{D}\right)\right\}$ is satisfied for each steady state. 
On the contrary, if:

$$
I_{1}>\alpha^{\frac{\alpha}{1-\alpha}} J_{1}^{\frac{1}{1-\alpha}} J_{2}^{-\frac{\alpha}{1-\alpha}}(1-\alpha)
$$

we have $I\left(k_{D}\right)>J\left(k_{D}\right)$ for all $k_{D}>0$. This last inequality is satisfied if $b_{D}+b_{F}$ is sufficiently high. In this case, there is no steady state.

In the case in which there exist two steady states, we know that their associated levels of capital are lower than $\widehat{k}^{s}=\left(J_{1} / J_{2}\right)^{\frac{1}{1-\alpha}}$. Thus, they are characterized by under-accumulation if $\widehat{k}^{s}<\left(\alpha A_{D}\right)^{\frac{1}{1-\alpha}}$. Using (78) and (79), this condition can be written as inequality (44) and Proposition 4 follows.

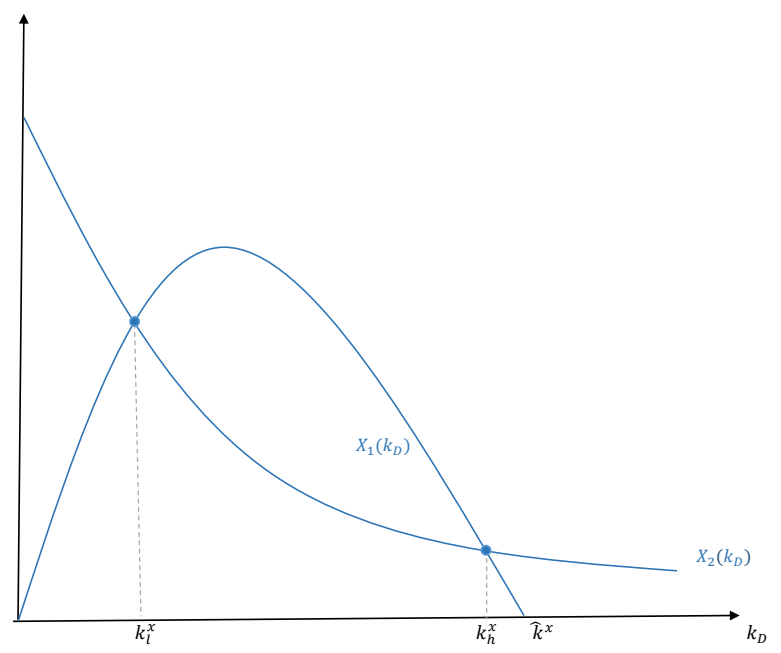

Figure 4 - Steady state analysis 


\section{References}

Barañano, I., San Martín, M., 2015. "The Impact of Foreign Aid Linked to Infrastructure and Pollution Abatement". Review of International Economics 23, 667-686.

Baumol, W.J., Oates, W.E., 1988. "The Theory of Environmental Policy". Cambridge University Press, 2nd edition.

Bednar-Friedl, B., Farmer, K., Rainer, A., 2010. "Effects of Unilateral Climate Policy on Terms of Trade, Capital Accumulation, and Welfare in a World Economy", Environmental and Resource Economics 47, 495-520.

Boone, P., 1996. "Politics and the Effectiveness of Foreign Aid ". European Economic Review 40, 289-329.

Bovenberg, A.L., Heijdra, B.J., 1998. "Environmental Tax Policy and Intergenerational Distribution". Journal of Public Economics 67, 1-24.

Bretschger, L., Suphaphiphat, N., 2014. "Effective Climate Policies in a Dynamic NorthSouth Model". European Economic Review 69, 59-77.

Burnside, C., Dollar, D., 2000. "Aid, Policies, and Growth". The American Economic Review 90, $847-868$

Caselli, F., 2005. "Accounting for Cross-Country Income Differences". In Handbook of Economic Growth, Vol. 1A, ed. Philippe Aghion and Steven N. Durlauf, 679-741. New York: North Holland.

Cassimon, D., Prowse, M., Essers, D., 2011. "The Pitfalls and Potential of Debt-for-Nature Swaps: A US-Indonesian Case Study". Global Environmental Change 21, 93-102.

Cassimon, D., Prowse, M., Essers, D., 2014. "Financing the Clean Development Mechanism through Debt-for-Efficiency Swaps? Case Study Evidence from a Uruguayan Wind Farm Project". The European Journal of Development Research 26, 142-159.

Cassimon, D., Van Campenhout, B., Ferry, M., Raffinot, M., 2015. "Africa: Out of Debt, Into Fiscal Space? Dynamic Fiscal Impact of the Debt Relief Initiatives on African Heavily Indebted Poor Countries (HIPCs)". International Economics 144, 29-52.

Channing, A., Jones, A., and Tarp, F., 2016. "What Is the Aggregate Economic Rate of Return to Foreign Aid?". The World Bank Economic Review 30, 446-474.

de Coninck, H., Revi, A., Babiker, M., Bertoldi, P., Buckeridge, M., Cartwright, A., Dong, W., Ford, J., Fuss, S., Hourcade, J.C., Ley, D., Mechler, R., Newman, P., Revokatova, A., Schultz, S., Steg, L., Sugiyama, T., 2018. "Strengthening and Implementing the Global Response. In: Masson-Delmotte, V., Zhai, P., Prtner, H.O., Roberts, D., Skea, J., Shukla, P.R., Pirani, A., 
Moufouma-Okia, W., Pan, C., Pidcock, R., Connors, S., Matthews, J.B.R., Chen, Y., Zhou, X., Gomis, M.I., Lonnoy, E., Maycock, T., Tignor, M., Waterfield, T. (eds) Global warming of 1.5 C. An IPCC Special Report on the impacts of global warming of $1.5 \mathrm{C}$ above pre-industrial levels and related global greenhouse gas emission pathways, in the context of strengthening the global response to the threat of climate change, sustainable development, and efforts to eradicate poverty. In Press

Deacon, R.T., Paul Murphy, P., 1997. "The Structure of an Environmental Transaction: The Debt-for-Nature Swap". Land Economics 73, 1-24.

Dreher, A., Sarah, L., 2017. "Aid and Growth. New Evidence Using an Excludable Instrument". Working Papers 0635, University of Heidelberg, Department of Economics.

Eyckmans, J., Fankhauser, S., Kverndokk, S., 2016. "Development Aid and Climate Finance". Environmental and Resource Economics 63, 429-450.

Fenton, A., Wright, H., Afionis, S., Paavola, J. Huq, S., 2014, "Debt Relief and Financing Climate Change Action". Nature Climate Change 4, 650-653.

Fernández, E., Rafaela, P., Jesús, R., 2010. "Double Dividend, Dynamic Laffer Effects and Public Abatement". Economic Modelling 27, 656-665.

Fodha, M., Seegmuller, T., 2012. "A Note on Environmental Policy and Public Debt Stabilization". Macroeconomic Dynamics 16, 477-492.

Fodha, M., Seegmuller, T., 2014. "Environmental Quality, Public Debt and Economic Development". Environmental and Resource Economics 57, 487-504.

Fodha, M., Seegmuller, T., Yamagami, H., 2018. "Environmental Tax Reform under Debt Constraint". Annals of Economics and Statistics 129, 33-52.

Heijdra, B.J., Kooiman, J.P., Ligthart, J.E., 2006. "Environmental Quality, the Macroeconomy, and Intergenerational Distribution". Resource and Energy Economics 28, 74-104.

Hsieh, C., Klenow, P.J., 2010. "Development Accounting". American Economic Journal: Macroeconomics 2, 207-23.

John, A., Pecchenino R. 1994. "An Overlapping Generations Model of Growth and the Environment". Economic Journal 104, 1393-1410.

John, A. Pecchenino, R., 1997. "International and Intergenerational Environmental Externalities". The Scandinavian Journal of Economics 99, 371-387.

Mendelsohn, R., Dinar, A., Williams, L., 2006. "The Distributional Impact of Climate Change on Rich and Poor Countries". Environment and Development Economics 11, 159-178. 
Muller-Furstenberger, G., Schumacher, I., 2017. "The Consequences of a One-sided Externality in a Dynamic, Two-agent Framework". European Journal of Operational Research 257, 310-322.

Persson, T., 1985. "Deficits and Intergenerational Welfare in Open Economies". Journal of International Economics 19, 67-84.

Rajan, R.G., Subramanian, A., 2006. "What Undermines Aid's Impact on Growth?". NBER Working Paper No. 11657.

Sakamoto, H., Ikefuji, M., Magnus, J.R., 2017. "Adaptation for Mitigation". Discussion papers e-16-014, Graduate School of Economics, Kyoto University.

Schelling, T.C., 1992. "Some Economics of Global Warming". The American Economic Review $82,1-14$.

Wang, M., Rieger, M., Hens, T., 2016. "How Time Preferences Differ: Evidence from 53 Countries". Journal of Economic Psychology 52, 115-135. 


\section{CEE-M Working Papers 1 - 2019}

WP 2019 - 01

WP $2019-02$

WP 2019 - 03

WP $2019-04$

WP $2019-05$

WP 2019 - 06

WP $2019-07$

WP $2019-08$

WP $2019-09$

WP 2019 - 10

WP $2019-11$

WP $2019-12$
Adrien Nguyen-Huu. \& Antonin Pottier «Hicksian Traverse Revisited: Conditions for the Energy Transition»

Oumar Mbodji, Adrien Nguyen-Huu \& Traian A. Pirvu «Optimal Sharing Rule for a Household with a Portfolio Management Problem»

Tristan Cotty, Tristan, Elodie Maitre d'Hotel \&Julie Subervie «Inventory credit to enhance food security in Africa»

Raphael Soubeyran

«Incentives, Pro-social Preferences and Discrimination»

Adrien Fabre, Mouez Fodhaz \& Francesco Ricci «0ptimal Timing of Energy Production»

Claude Bismut \& Ismaël Rmajo

«A world of low interest rates»

Gabriela Demarchi, Julie Subervie, Fernando Palha Leite $\&$ Jean-Paul Laclau

« Farmers' preferences for water-saving strategies in brazilian eucalypt plantation »

Arnaud Tognetti, David Doat, Dimitri Dubois \& Rustam Romaniuc "Does the presence of a physically disabled erson in the group increase cooperation? An experimental test of the empathyaltruism hypothesis »

Isabelle Tritsch, Gwenole Le Velly, Benoit Mertens, Patrick, Meyfroidt, Christophe Sannier, Jean-Sylvestre Makak \& Kenneth Houngbedji « Do Forest-Management Plans and FSC Certification Reduce deforestation in the Congo Basin? »

Jean-Michel Salles

«Valuing the loss and damage from climate change: a review of some current issues »

Can Askan Mavi

«Can harmful events be another source of environmental traps? »

Daniel Serra

« Neuroeconomics and Modern Neuroscience »

\footnotetext{
${ }^{1}$ CEE-M Working Papers / Contact : laurent.garnier@inra.fr

- RePEc https://ideas.repec.org/s/hal/wpceem.html

- HAL https://halshs.archives-ouvertes.fr/CEE-M-WP/
} 
WP $2019-13$

WP $2019-14$

WP $2019-15$

WP $2019-16$

WP $2019-17$

WP $2019-18$

WP $2019-19$

WP $2019-20$

\section{Daniel Serra}

«La neuroeconomie en question : debats et controversies»

Claire Richert, Katrin Erdlenbruch \& Frédéric Grelot

« The impact of flood management policies individual adaptation actions:

insights from a French case study »

Margaux Lapierre, Alexandre Sauquet \& Julie Subervie

« Improving Farm Environmental Performance through Technical Assistance:

Empirical Evidence on Pesticide Use»

Pierre Levasseur, Katrin Erdlenbruch \& Christelle Gramaglia

«Why do people continue to live near polluted sites? Empirical evidence

from Southwestern Europe

Murielle Djiguemde, Dimitri Dubois, Alexandre Sauquet $\&$ Mabel Tidball

« 0 n the modelling and testing of groundwater resource models»

Guillaume Cheikbossian

«Evolutionarily stable in-group altruism in intergroup Conflict »

Raphael Soubeyran

«Technology Adoption and Pro-social Preferences »

Marion Davin, Mouez Fodha \& Thomas Seegmuller

«Pollution in a globalized world: Are debt transfers among countries a

solution? » 